\title{
Pore growth in U-Mo/Al dispersion fuel
}

\author{
Yeon Soo Kim ${ }^{1, *}$, G.Y. Jeong ${ }^{2}$, D.-S. Sohn ${ }^{2}$, L.M. Jamison ${ }^{1}$ \\ 1: Argonne National Laboratory, 9700 South Cass Avenue, Argonne, IL 60439 USA \\ 2: Ulsan National Institute of Science and Technology, 50 UNIST-gil, Eonyang-eup, \\ Ulju-gun, Ulsan 689-798 Republic of Korea \\ * Corresponding author \\ e-mail address:yskim@anl.gov
}

The submitted manuscript has been created by the
UChicago Argonne, LCC as Operator of Argonne
National Laboratory under contract No. DE-AC-02-
$06 \mathrm{CH} 11357$ between the UChicago Argonne, LLC
and the Department of Energy. The U.S. Government
retains for itself, and others acting on its behalf, a
paid-up, nonexclusive, irrevocable worldwide license
in said article to reproduce, prepare derivative works,
distribute copies to the public, and perform publicly
and display publicly, by or on behalf of the
Government. 


\begin{abstract}
for submission
$\mathrm{U}-\mathrm{Mo} / \mathrm{Al}$ dispersion fuel is currently under development in the DOE's Material Management and Minimization program to convert HEU-fueled research reactors to LEU-fueled reactors. In some demanding conditions in high-power and high-performance reactors, large pores form in the interaction layers between the U-Mo fuel particles and the Al matrix, which pose a potential to cause fuel failure. In this study, comprehension of the formation and growth of these pores was explored. As a product, a model to predict pore growth and porosity increase was developed. Well-characterized in-pile data from reduced-size plates were used to fit the model parameters. A data set of full-sized plates, independent and distinctively different from those used to fit the model parameters, was used to examine the accuracy of the model.
\end{abstract}




\title{
Pore growth in U-Mo/Al dispersion fuel
}

\author{
Yeon Soo Kim, G.Y. Jeong, D.-S. Sohn, L.M. Jamison
}

\begin{abstract}
$\mathrm{U}-\mathrm{Mo} / \mathrm{Al}$ dispersion fuel is currently under development in the DOE's Material Management and Minimization program to convert HEU-fueled research reactors to LEU-fueled reactors. In some demanding conditions in high-power and high-performance reactors, large pores form in the interaction layers between the U-Mo fuel particles and the Al matrix, which pose a potential to cause fuel failure. In this study, comprehension of the formation and growth of these pores was explored. As a product, a model to predict pore growth and porosity increase was developed. The model includes three major topics: fission gas release from the U-Mo and the IL to the pores, stress evolution in the fuel meat, and the effect of amorphous IL growth. Well-characterized inpile data from reduced-size plates were used to fit the model parameters. A data set from fullsized plates, independent and distinctively different from those used to fit the model parameters, was used to examine the accuracy of the model. The model showed fair agreement with the measured data. The model suggested that the growth of the IL has a critical effect on pore growth, as both its material properties and energetics are favorable to pore formation. Therefore, one area of the current effort, focused on suppressing IL growth, appears to be on the right track to improve the performance of this fuel.
\end{abstract}

Keywords: U-Mo/Al dispersion fuel, pore growth, porosity, in-pile data, modeling 


\section{Introduction}

U-Mo/Al dispersion fuel, composed of U-Mo alloy fuel kernels embedded in an Al matrix, has been developed for the conversion of high-performance and high-flux research and test reactors from HEU fuel to LEU fuel. In particular, the use of this fuel is aimed for high power and high performance research reactors for which the irradiation conditions demand properties beyond the performance limit of the currently available U-Si intermetallic dispersion fuel. In U-Mo/Al dispersion fuels the fuel zone, also referred to as the fuel meat, is metallurgically bonded with the Al alloy cladding.

The main obstacle to the successful performance of this fuel to warrant qualification is excessive fuel meat swelling, or breakaway swelling. The excessive swelling is caused by the growth of pores within the interaction layer between the U-Mo fuel and the Al matrix under high-power and/or high-burnup conditions [1]-[4]. The formation and growth of these pores increases the probability of interconnection among them. Once a pore interconnection is established, breakaway swelling follows, which is considered incipient to fuel failure. This pore type is distinct from the fission gas bubbles formed within the U-Mo fuel kernels. In particular, the fission gas bubbles within the U-Mo particles are much smaller and stable under irradiation, [5] as shown in Fig. 1. The effect of this bubble type on fuel performance is minor. The formation of these small bubbles only degrades the thermal conductivity of the U-Mo fuel, for which modeling work was recently reported in the literature [6]. 
There have been international efforts to develop a remedy to prevent, or at least to suppress, IL growth, believed to be a major path for the formation of large pores. At ANL, USA, the addition of a small amount of silicon to the Al matrix was proposed, and proven effective in inhibiting IL growth to some extent by subsequent in-pile and out-of-pile tests (see references in [7][8]). At SCK-CEN, Belgium, a method of coating the U-Mo particles with either a ZrN- or Si- layer as a diffusion barrier was tested, and considerable success was also demonstrated [9]-[11]. At about the same time, KAERI, Korea, tried coating the U-Mo particles with either a UN- or a Si-layer, which also showed some effectiveness inhibiting IL formation [12]. Although all methods reduced the formation of the IL, none of them seems to be the ultimate solution, as none of the methods were shown to completely prevent pore formation under the demanding irradiation conditions. Therefore, comprehending and modeling this type of pore formation and growth may help devise a better method to improve the performance of this fuel, enabling it to achieve the desired burnup goal ( $\sim 85 \%$ burnup of LEU).

However, no studies can be found in the literature that have dealt with both the mechanisms for and prediction of the formation and growth of the type of pores discussed here. There are several empirical and semi-empirical models that try to predict the fuel failure condition caused by large pore growth available in the literature [13]-[15].

It is known that both the $\mathrm{Al}$ matrix and $\mathrm{Al}$ alloy cladding are dimensionally stable during irradiation and are quite inert from irradiation damage [16][17]. For cases that are free of the above-mentioned large pores, fuel meat swelling is a sum of the swelling of the U-Mo kernels as a result of fission, and volume expansion due to IL growth [18]. In this situation, the 
performance of U-Mo/Al dispersion fuel is stable and predictable, and a model to calculate fuel meat swelling is available in the literature [18]. When large pores are formed, however, the porosity must be added to the fuel meat swelling.

In this study, we have developed a mechanistic model to predict the growth kinetics of pores in the IL using reduced-sized plate data. The model was then validated using in-pile data from fullsized plates. The model can be applied to predict fuel failure, and can be employed to guide future fuel design improvement studies.

\section{Experimental data}

Three reduced-sized U-Mo/Al dispersion plates irradiated in the ATR under distinctly different conditions were selected for the model development. Descriptions of the plates and their irradiation conditions are summarized in Table 1. The plate dimensions are $100 \mathrm{~mm}$ x $25 \mathrm{~mm} \times$ $1.40 \mathrm{~mm}$ and the meat size is $81.3 \mathrm{~mm} \times 18.5 \mathrm{~mm} \times 0.64 \mathrm{~mm}$. These plates were loaded axially into the ATR, and oriented such that one of the narrow edges faced the ATR core. Hence, a range of fission densities were produced in the plates, with the edge closest to the reactor core having the highest fission density [7].

During post-irradiation examination (PIE), the plates were cut at the axial midplane and the cross section was examined metallographically. Optical micrographs of the plate cross sections are shown in Fig. 2. Large pores were observed in V6022M and V6019G. R3R108 had an Al-Si 
mixture matrix that reduced IL growth [7]. This plate shows relatively less porosity in general, even though the burnup was highest. One remarkable observation was that this plate showed cleavage-type ruptures in the $\mathrm{Al}$ matrix, different from the typical pore morphology observed for plates fabricated with a pure $\mathrm{Al}$ matrix. The primary cause of the cleavage-type ruptures is attributed to local stress buildup due to fuel swelling, and low plasticity in the Al-Si matrix.

Porosity, defined as the pore volume divided by the meat volume containing the pores, was measured from optical micrographs of the meat cross-section. The porosity data for all three plates, as a function of distance in the fuel meat, is shown in Fig. 3. V6022M shows increased porosity overall, and a larger portion of the meat cross section contains pores compared to the other plates.

\section{Pore formation mechanism}

The image shown in Fig. 1(a) is an optical micrograph of plate V6022M containing U-10Mo/Al dispersion fuel that has been irradiated to $5.8 \times 10^{21} \mathrm{f} / \mathrm{cm}^{3}$. Details of the behavior of the IL and pore microstructure can be found elsewhere [19]. A substantial volume of IL was formed in this plate. Pores were found chiefly at the interface between the Al and IL. It is particularly noticeable that these pores are substantially more concave toward the IL than the Al. The Al surface of the pores is relatively flat, implying that higher creep occurs in the IL than in the Al during irradiation. Jeong et al. [20] showed that the IL experiences about 8 times higher creep due to a combination of a higher fission rate and a higher creep rate than $\mathrm{Al}$. 
Typical hot rolled U-Mo/Al dispersion fuel meats have some as-fabricated pores [21]. Most of these pores are due to inhomogeneous mixing of the U-Mo powder and the Al powder. U-Mo particles have a thin layer of oxide $(\sim 1 \mu \mathrm{m})$ [22], which causes poor bonding to the $\mathrm{Al}$ matrix material. Pore formation and poor bonding during fabrication both contribute to producing an interface that can be relatively weaker. The weakened interfaces can serve as sink sites for fission gases during irradiation. When the U-Mo and the $\mathrm{Al}$ are metallurgically bonded during plate production, an IL-Al interface forms, which can also serve as pore nucleation sites.

The IL is known to be amorphous during irradiation, whereas the U-Mo and the $\mathrm{Al}$ remain crystalline [23]-[26]. The two most prominent characteristics of the amorphous IL are an increase in deformability (or creep using Jeong's terminology [20]) and enhanced diffusivities of migrating species, such as fission products, within the IL. The cause for these changes was attributed to the augmentation in so-called free volume [19]. No matter the cause of these property differences, it should be noted that the amorphous IL facilitates pore growth at the IL$\mathrm{Al}$ interface by replacing the $\mathrm{Al}$ with a more readily deformable structure, and by allowing more fission gases to collect in sinks at the IL-Al interface.

Post-irradiation measurements of the concentrations of solid fission products in a sample composed of a U-Mo particle, the surrounding IL, and a portion of the Al matrix showed that the peak concentrations were usually found at the IL-Al interfaces [27]-[29]. It is remarkable that the peak concentrations of the fission gases were also at the IL-Al interfaces, where large pores typically form, as shown in Fig. 1. The data by Leenaers [27] also showed that the fission gas 
concentration in the IL was lower than that in the U-Mo or in the Al, suggesting that fission gas migration through the IL is enhanced, and fission gas retention in the IL is low. The fission gases found at the IL-Al interface have two origins: from fissions within the U-Mo fuel and the IL. The IL also contains uranium atoms, so it is also a fissioning body. Two release mechanisms are applicable to the transfer of gaseous fission products from the fuel or the IL to the IL-Al interface: direct recoil and diffusion.

During the pore growth stage, pore growth kinetics is determined by the amount of fission gas that is released to the pore and IL growth kinetics. IL growth enhances fission gas release and provides the necessary low viscosity volume that allows the pore to grow.

\section{Fission gas generation}

Fission gas can be produced in both the U-Mo fuel and within the IL. The amount of fission gas produced is highly influential to the fission gas bubble size within the fuel and the pore size in the IL. Determination of the fission gas produced per unit volume of U-Mo and IL is discussed in the following sections.

\subsection{U-Mo}

The volumetric fission gas generation in U-Mo fuel $\left(\beta_{U-M o}\right)$ was calculated as follows:

$$
\beta_{U-M o}=F_{d}^{U-M o}\left(y_{X e}+y_{K r}\right)
$$


where $F_{d}^{U-M o}$ is the fission density in the U-Mo, and $\mathrm{y}_{\mathrm{Xe}}$ and $\mathrm{y}_{\mathrm{Kr}}$ are the fission yields of $\mathrm{Xe}$ and $\mathrm{Kr}$, respectively ( 0.21 for $\mathrm{Xe}$ and 0.05 for $\mathrm{Kr})$.

\subsection{IL}

As with the U-Mo case, the volumetric fission gas generation in the IL was calculated. However, the dilution of the uranium atom concentration due to $\mathrm{Al}$ interdiffusion in the IL must be accounted for. $\beta_{\mathrm{IL}}$ can be determined from $\beta_{\mathrm{U}-\mathrm{Mo}}$ by multiplying $\beta_{\mathrm{U}-\mathrm{Mo}}$ by the ratio of the molar volume of U-Mo $\left(\mathrm{V}_{\mathrm{m}}{ }^{\mathrm{U}-\mathrm{Mo}}\right)$ to the molar volume of the $\mathrm{IL}\left(\mathrm{V}_{\mathrm{m}}{ }^{\mathrm{IL}}\right)$, where $\mathrm{V}_{\mathrm{m}}=\mathrm{M} / \rho$, as shown in Eq.(2).

$$
\beta_{I L}=\frac{\rho_{I L} M_{U-M o}}{\rho_{U-M o} M_{I L}} \beta_{U-M o}
$$

where $\rho$ and M are the densities and molecular weights of U-Mo and the IL. The atomic ratio of Al to U-Mo averaged over the IL is typically 4 [18][30]. In the IL, the uranium atom density is reduced by this ratio. In addition, the reduction in the IL density due to chemical mixing of UMo and $\mathrm{Al}$ is about $8 \%$ [18]. Therefore, Eq. (2) can be approximated as

$$
\beta_{I L} \cong \frac{1.08}{5} \beta_{U-M o}
$$

\section{Fission gas release}


The source of the fission gas found in the pores is fission gas generated in the U-Mo kernel and the IL. Fission gas that is released from the fuel-containing zones (the U-Mo fuel and the IL) and reaches the IL-Al interface creates, and grows, pores at this interface. Fission gas can be released from the fuel-containing zones by recoil, diffusion, or a combination of the two mechanisms. The amount of gas released by recoil is dependent upon both the fission density and the location of the fission events. The recoil release mechanism is well established in the literature [31]. The temperatures in the bulk U-Mo kernel, the IL, and the $\mathrm{Al}$ are assumed to be the same, and are below $\sim 200{ }^{\circ} \mathrm{C}$ [32]. In this temperature regime, diffusion is athermal and only occurs by fissioninduced diffusion. Therefore, the recoil mechanism plays a dominant role in fission gas release to the pores. Detailed descriptions of the recoil and diffusion mechanisms for fission gas release, and the different pathways for gas particles to reach the pores, are discussed in the following sections.

\subsection{Recoil mechanism}

Recoil release of a gas atom from a fissioning body, in this case a U-Mo fuel kernel or the IL, occurs near the surface. When it is born, the energetic fission gas atom can directly jump out of the fissioning body as long as the fission event occurs closer to the surface than the recoil range. Another possibility is that a fission fragment collides with a sessile fission gas atom within the fissioning body, and imparts enough energy that the fission gas atom is ejected from the fissioning body. This gas particle ejection process is referred to as the knock-out mechanism [33]. In our model, for simplicity, these two mechanisms are combined into one recoil release mechanism because the recoil mechanism is far more dominant than the knock-out mechanism. 
According to Prodos and Scott [31], the probability of a fission-fragment gas atom escaping from a spherical fissioning body by recoil (see Fig. 4(a)) is:

$$
P_{e}= \begin{cases}\frac{1}{2}-\frac{R^{2}-\mu^{2}-x^{2}}{4 \mu x} & \text { for }(\mathrm{R}-\mu)<x<R \\ 0 & \text { for } 0<x<(\mathrm{R}-\mu)\end{cases}
$$

where $\mathrm{R}$ is the radius of the fissioning body, $\mathrm{x}$ is the distance between the fission event from the center of the fissioning body, and $\mu$ is the recoil range ( $\mu=6.8 \mu \mathrm{m}$ for U-Mo and $\mu=12 \mu \mathrm{m}$ for the IL). Eq. (4) is applicable to both U-Mo and the IL.

The amount of released fission gas by recoil $\left(R_{f}\right)$ from a finite shell $\left(d V_{x}\right)$ confined by radii $\mathrm{x}$ and $\mathrm{x}+\mathrm{dx}$ is

$$
\begin{aligned}
R_{f} & =\beta_{i} P_{e} d V_{x} \\
& =\beta_{i} \int_{x}^{x+d x} P_{e}\left(4 \pi x^{2}\right) d x
\end{aligned}
$$

where $\beta$ is the fission gas generated per unit volume per Eq. (1) or Eq. (2), dependent upon the location of the fission event, either in the U-Mo or IL, respectively.

\subsection{Diffusion mechanism}

The amount of fission gas released by diffusion $\left(R_{d}\right)$ from a fissioning body with a volume $V_{f}$ is: 


$$
R_{d}=\beta_{i} F_{d} V_{f}
$$

where $F_{d}$ is the fractional release by the diffusion mechanism, which can be described by the Booth model [34]:

$$
F_{d}=\frac{4}{a} \sqrt{\frac{D t}{\pi}}-\frac{3 D t}{2 a^{2}}
$$

where $\mathrm{D}$ is the diffusion coefficient, $\mathrm{t}$ is the time, and $a$ is the radius of the equivalent sphere of the diffusing medium. $a$ is assumed to be equal to a half of the average grain size of the U-Mo kernel, and the same value is used in the IL, assuming the IL has similar properties to the U-Mo. For a typical U-Mo particle produced by the atomization method [35], the grain size is typically in the $3-15 \mu \mathrm{m}$ range[36]. In this study, an average grain size of $9 \mu \mathrm{m}$ was used for both U-Mo and the IL. Adopting the Booth model assumes that fission gas release through the grain boundaries is much easier than through the intragranular regions, although some resistance was observed for $\mathrm{UO}_{2}$ [37]. By using the average grain radius for the Booth radius ' $a$ ', we implicitly assume that the diffusivity is an effective value and subject to a data fit (subsect. 6.3).

Recoil release occurs instantaneously, so Eq. (5) does not have a time-dependent term. However, the diffusion mechanism depends on the elapsed time between the birth of the atom in the fission event and the release of a gas atom from the fissioning body. Hence, a time term is included in Eq. (7). The fractional release calculated by Eq. (7) represents the cumulative release fraction up to time $\mathrm{t}$.

The diffusion coefficient, D, adapted in (7) solely relies on atom displacements caused by fission. This diffusion behavior, fission induced diffusion (FID), is possible because the 
temperature is so low that thermally activated diffusion is negligible. Ample studies on FID in ceramic fuels are available and well-documented in the literature (see for example [38],[39]). Turnbull showed that the diffusion coefficient can be expressed as a linear function of fission rate up to $\sim 1000{ }^{\circ} \mathrm{C}$ in ceramic fuels [38]. Following the work of Turnbull, in the present study D is defined, in a general form, as:

$$
\mathrm{D}=\mathrm{A} \dot{\mathrm{F}}
$$

where A is the diffusivity constant, and $\dot{F}$ is the fission rate. Eq. (8) is specified for the region of interest as follows:

$$
\begin{array}{ll}
\mathrm{D}^{U-M o}=\mathrm{A}^{U-M o} \dot{\mathrm{F}}_{\mathrm{f}} & \text { for U-Mo } \\
\mathrm{D}^{I L}=\mathrm{A}^{I L} \dot{\mathrm{F}}_{I L} & \text { for IL }
\end{array}
$$

By applying the same logic used to develop Eq.(3), Eq.(10) can be simplified to:

$$
\mathrm{D}^{I L}=\mathrm{A}^{I L}\left[\frac{1.08}{5} \dot{\mathrm{F}}_{\mathrm{f}}\right] \quad \text { for IL }
$$

$\mathrm{A}^{U-M o}$ and $\mathrm{A}^{I L}$ are unknown, so they will be obtained using a data fit later in subsect. 6.3.

\subsection{Amount of fission gas released to the pore}

Fission gas release to the pore surface can take place via five different pathways, depending on the location of the fission event, as illustrated in Fig. 4(b) and (c). The pathways for the fission gas are:

(1) born in the U-Mo and recoils directly to the pore

(2) born in the U-Mo, recoils to the IL, and diffuses to the pore within the IL 
(3) born in the U-Mo and remains in the U-Mo after recoil, diffuses through the U-Mo to the IL, and subsequently diffuses through the IL to the pore

(4) born in the IL and diffuses through the IL to the pore,

(5) born in the IL and recoils directly to the pore

Except for pathways (1) and (5), the pathways for the fission gas to reach the pore involve both the recoil mechanism and the diffusion mechanism. When $\mathrm{d}$ becomes larger than the recoil range in U-Mo (as is the case in Fig. 4(c)), direct recoil release from the U-Mo to the pore is not possible. In this case, pathway (1) is excluded. Fission gas retention in the Al matrix is assumed to be negligible.

The released fission gasses do not solely go into the pores. In fact, most of the gasses will instead reach the IL-Al interface in a region without pores. The fraction of fission gasses that reach a pore already formed at the interface is equal to the area fraction of the pore surface along the IL$\mathrm{Al}$ interface. This fraction calculation assumes that fission gases are uniformly generated in the U-Mo and in the IL, and are isotopically released in the radial direction. This fraction, defined as $a_{\mathrm{p}}$, can be calculated as follows:

$$
a_{p}=\frac{\left(1-\cos \theta_{I L}\right) r_{I L}^{2}}{2(R+Y)^{2}}
$$

where $r_{I L}$ is the radius of curvature for the IL-pore interface, $\theta_{I L}$ is the contact angle between IL and pore, $\mathrm{R}$ is the U-Mo particle radius, and $\mathrm{Y}$ is the IL thickness (see Fig. 4). 


\section{Modeling}

\subsection{Model development}

The pore is in a mechanical equilibrium for which the pressure in the pore is balanced by a compressive stress and the surface tension force (Fig. 5). This condition can be described by the following Young-Laplace equation:

$$
P=\frac{2 \gamma}{r_{p}}+\sigma
$$

where $\mathrm{P}$ is the pressure inside the pore exerted by gas atoms in the pore, $\sigma$ is the stress in the radial direction at the surface of the pore, $\gamma$ is the surface tension of the pore and $r_{p}$ is the pore radius. $2 \gamma / r_{p}$ is the inward stress exerted by the surface tension of the pore. If the stress is compressive, its sign is positive. The stress, $\sigma$, is typically a sum of the system pressures such as the coolant pressure and the hydrostatic stress generated by microstructural evolution in the meat, i.e.,

$$
\sigma=\sigma_{s y s}+\sigma_{h}
$$

where $\sigma_{s y s}$ is the system pressure and $\sigma_{h}$ is the hydrostatic stress.

An ABAQUS finite element analysis (FEA) method was used to calculate the hydrostatic stress in the fuel meat. An ABAQUS mesh design was developed that models the fuel meat as a FCC 
array of uniformly sized U-Mo particles embedded in the Al matrix. The details of how to calculate the hydrostatic stress in the meat are available elsewhere [40][41]. Fig. 6 shows the evolution of hydrostatic stress with irradiation time along the transverse centerline, obtained using the ABAQUS method. The primary cause for the changes in stress are the microstructural changes in the fuel meat generated by fuel particle swelling, IL growth, and creep deformation. V6022M and V6019G show more variation in swelling over time compared to R3R108, possibly because they have greater IL formation and creep deformation. A remarkable finding is that the hydrostatic stress varies with time not only in magnitude, but also in sign and spatial location. This change in hydrostatic stress with plate location may be the reason why pore formation and growth vary widely across the plates.

A unit cell composed of a single U-Mo particle and the corresponding Al matrix volume, as determined by the U-loading of the plate, was modeled (see Fig. 7(a)). During irradiation, an IL forms around the U-Mo particle, and a pore is formed within the unit cell. This model also simplifies the fuel meat as an FCC array, a technique which has been employed in previous studies [7][18][20].

As was shown in Fig. 1, pores that form along the IL-Al interface have a different concavity along the IL surface compared to that along the Al surface. The pore concavity was dealt with using the contact angle concept, as illustrated in Fig. 7, where the contact angle $\theta_{I L}$ is on the IL side and $\theta_{A l}$ is on the Al side. $\theta_{I L}$ and $\theta_{A l}$ are usually different because the IL and the Al have different surface energies. The contact angles are determined by the relative magnitudes of the surface energies of the IL and the Al, satisfying the following correlation: 


$$
\gamma_{A l} \sin \theta_{A l}=\gamma_{I L} \sin \theta_{I L}
$$

where $\gamma$ are the surface energies. Noting that the pore is forming between two different surfaces that have different surface energies, it is convenient to adopt a third surface energy, the interface energy $\gamma_{I L / A l}$, defined as follows:

$$
\gamma_{I L / A l}=\gamma_{A l} \cos \theta_{A l}+\gamma_{I L} \cos \theta_{I L}
$$

where $\gamma_{I L / A l}$ is the interface energy at the IL-Al matrix interface. The interface energy $\gamma_{I L / A l}$ can be estimated using the Girifalco-Good correlation [42]:

$$
\gamma_{A l / I L}=\gamma_{A l}+\gamma_{I L}-2 \phi \sqrt{\gamma_{A l} \gamma_{I L}}
$$

where $\phi$ is a constant which can be calculated from:

$$
\phi=-\frac{\Delta G_{I L-A l}^{a}}{\sqrt{\Delta G_{I L}^{c} \Delta G_{A l}^{c}}}
$$

Here $\Delta G_{I L-A l}^{a}$ is the free energy of adhesion at the IL-Al interface, and $\Delta G_{I L}^{c}$ and $\Delta G_{A l}^{c}$ are the free energies of cohesion for IL and $\mathrm{Al}$, respectively. Metallic solids are highly cohesive due to metallic bonding. In typical metal-metal interfaces, the metals have a stronger internal connection than external, which means that they form a non-adhesive interface. When the two adjoining materials have a tendency to be adhesive to each other, $\phi$ has a value in the range 0.05 -0.3 . When they are non-adhesive to each other, $\phi$ has a value less than 0.05 . It is also known that $\phi$ tends to decrease when the atomic planes of the two materials are mismatched at the interface [43]. Based on this information, and the fact that the pore is formed with two distinct 
surfaces, $\phi$ was fitted to be 0.1 for the present model. This $\phi$ value indicates that although there is adhesion between the amorphous IL and the crystalline Al, it is limited.

Several models are available to calculate the surface energies of intermetallic compounds [44]. However, no data for the surface energy of $\operatorname{IL}\left(\gamma_{I L}\right)$ is available. Therefore, this value had to be numerically obtained for this study. If the IL is an intermetallic compound, it can be approximated using a linear interpolation between the U-Mo and the $\mathrm{Al}$ such as:

$$
\gamma_{I L, 0}=x_{A l} \gamma_{A l}+x_{U-M o} \gamma_{U-M o}
$$

where $\mathrm{x}$ are the atom fractions of $\mathrm{Al}$ and $(\mathrm{U}+\mathrm{Mo})$ in the $\mathrm{IL}$.

Considering that the IL is an amorphous material, the difference between the crystalline and amorphous states must be assessed. In the literature, it is known that crystalline materials including oxides and metal alloys have higher surface energies than their amorphous states [45][46], because the crystallization reaction requires the formation of a new surface, which requires additional energy. A factor, $\alpha$, to reflect the reduction in the IL surface energy from the crystalline to the amorphous state was introduced as follows:

$$
\gamma_{I L}=\alpha \gamma_{I L, 0}
$$

where $\gamma_{I L, 0}$ is the surface energy of the IL when it is crystalline. The contact angles vary depending on $\alpha$ in the relations given in Eqs. (15) and (16). Because no data is available for $\alpha$ in the literature, it was determined numerically in this study (see sect.6.3). 
The material properties used to calculate Eqs. (15) - (19) are summarized in Table 2.

Eq. (15) implies that $\theta_{I L}$ must be higher than $\theta_{A l}$ because $\gamma_{I L}$ is smaller than $\gamma_{A l}$, which is consistent with the PIE observation that the contact angle is typically greater for the IL-pore interface than that for the Al-pore interface (see Fig. 1). In other words, the IL has lower viscosity (or higher fluidity) than the Al [19].

Assuming that the same stress is exerted on the two interfaces (i.e. the IL-pore and Al-pore interfaces), the pore can be divided into two spherical caps, as shown Fig. 7(b). The work, $d W$, to produce the volume expansion in the given spherical cap, or to expand the curvature by an incremental amount $d r$ is

$$
\begin{aligned}
d W_{i} & =\Delta P d V_{i} \\
& =\Delta P\left[2 \pi r_{i}^{2}\left(1-\cos \theta_{i}\right) d r_{i}\right]
\end{aligned}
$$

where $\mathrm{i}$ is the interface index $(\mathrm{i}=\mathrm{IL}$ or $\mathrm{Al}), \Delta P$ is the pressure difference across the interface, $\mathrm{r}$, are the radii of curvature, and $\theta$ are the contact angles.

$d W_{i}$ can also be written in terms of surface energies of the related materials such as:

$$
\begin{aligned}
d W_{i} & =\gamma_{i} d A \\
& =\gamma_{i}\left[\left(4 \pi r_{i} d r_{i}\right) f\left(\theta_{i}\right)\right]
\end{aligned}
$$

Here, $f(\theta)$ is a function of $\theta$ given by 


$$
f(\theta)=1-\frac{3}{2} \cos \theta+\frac{1}{2} \cos ^{3} \theta
$$

Equating Eqs. (21) and (22) gives:

$$
2 \pi \Delta P \times\left[r_{I L}^{2}\left(1-\cos \theta_{I L}\right) d r_{I L}+{r_{A l}}^{2}\left(1-\cos \theta_{A l}\right) d r_{A l}\right]=4 \pi\left[\gamma_{I L} r_{I L} d r_{I L} f\left(\theta_{I L}\right)+\gamma_{A l} r_{A l} d r_{A l} f\left(\theta_{A l}\right)\right]
$$

Solving Eq. (24) for $\Delta \mathrm{P}$ results in:

$$
\Delta P=2 \frac{\gamma_{I L} r_{I L} d r_{I L} f\left(\theta_{I L}\right)+\gamma_{A l} r_{A l} d r_{A l} f\left(\theta_{A l}\right)}{r_{I L}^{2}\left(1-\cos \theta_{I L}\right) d r_{I L}+r_{A l}^{2}\left(1-\cos \theta_{A l}\right) d r_{A l}}
$$

With an approximation that $d r_{I L}=d r_{A l} \cong d r$, and knowing that $\Delta P=P-\sigma$, Eq. (25) can be rearranged for $\mathrm{P}$ as:

$$
P=2 \frac{\gamma_{I L} r_{I L} f\left(\theta_{I L}\right)+\gamma_{A l} r_{A l} f\left(\theta_{A l}\right)}{{r_{I L}}^{2}\left(1-\cos \theta_{I L}\right)+{r_{A l}}^{2}\left(1-\cos \theta_{A l}\right)}+\sigma
$$

In the case where the pore is a perfect sphere and is surrounded by a homogeneous medium, we can assume that $r_{I L}=r_{A l}, \gamma_{I L}=\gamma_{A l}, \theta_{I L}=\theta_{A l}$, and $f(\theta)=1$. In this case, of course, Eq. (26) reduces to Eq. (13).

Using the ideal gas law, assuming the pressure inside the pore is not so high that this law is inapplicable, $\mathrm{P}$ is expressed by

$$
P=\frac{n(t) k T}{V_{p}}
$$

where $\mathrm{n}(\mathrm{t})$ is the number of fission gas atoms in the pore at time $\mathrm{t}, \mathrm{k}$ is Boltzmann's constant, $\mathrm{T}$ is temperature, and $\mathrm{V}_{\mathrm{p}}$ is the pore volume. $\mathrm{V}_{\mathrm{p}}$ can be calculated by adding the partial pore volumes on the IL-pore side $\left(V_{I L / \text { pore }}\right)$ and on the Al-pore side $\left(V_{\mathrm{Al} / \text { pore }}\right)$ as follows: 


$$
\begin{aligned}
V_{p} & =V_{I L / \text { pore }}+V_{A l / \text { pore }} \\
& =\frac{2 \pi}{3} r_{I L}^{3} f\left(\theta_{I L}\right)+\frac{2 \pi}{3} r_{A l}^{3} f\left(\theta_{A l}\right) \\
& =\frac{2 \pi}{3}\left[r_{I L}{ }^{3} f\left(\theta_{I L}\right)+r_{A l}{ }^{3} f\left(\theta_{A l}\right)\right]
\end{aligned}
$$

$r_{A l}$ has a correlation with $r_{I L}$ (Fig. 7(b)) defined by:

$$
r_{A l}=q r_{I L}
$$

where $\mathrm{q}$ is

$$
q=\frac{\sin \theta_{\mathrm{IL}}}{\sin \theta_{A l}}
$$

By using the geometrical relation given in Eq. (15), Eq. (28) also gives

$$
V_{p}=Q r_{I L}^{3}
$$

where $\mathrm{Q}$ is expressed as

$$
Q=\frac{2 \pi}{3}\left[f\left(\theta_{I L}\right)+q^{3} f\left(\theta_{A l}\right)\right]
$$

Rearranging Eq. (26) with regard to $r_{I L}$ and using Eqs. (27) - (31) yields

$$
C_{1}(t) H^{3}-C_{2} H+\sigma=0
$$

where $H=1 / r_{I L}, C_{1}=\frac{n(t) k T}{Q}$, and $C_{2}=2 \frac{\gamma_{I L} f\left(\theta_{I L}\right)+\gamma_{A l} f\left(\theta_{A l}\right) \mathrm{q}}{\left(1-\cos \theta_{I L}\right)+q^{2}\left(1-\cos \theta_{A l}\right)}$.

Solving Eq. (32) gives $r_{I L}$ and is solvable with the materials properties given in Table 2. The number of gas atoms at time $t, n(t)$, is calculated by applying the fission gas release model described in sect.5. 
Using $r_{I L}$ and $\theta_{I L}$, the pore volume $\left(\mathrm{V}_{\mathrm{p}}\right)$ can be found using Eq. (31). Subsequently, porosity is calculated using the following equation:

$$
\zeta=\frac{V_{p}}{V_{c}\left[1+\left(\frac{\Delta V}{V_{0}}\right)_{m}\right]+V_{p}}
$$

where $\mathrm{V}_{\mathrm{c}}$ is the as-fabricated volume of the unit cell and $\left(\Delta \mathrm{V} / \mathrm{V}_{0}\right)_{\mathrm{m}}$ is the meat swelling, which can be calculated using

$$
\left(\frac{\Delta \mathrm{V}}{\mathrm{V}_{0}}\right)_{\mathrm{m}}=\frac{\mathrm{V}_{\mathrm{f}}+\mathrm{V}_{\mathrm{Al}}+\mathrm{V}_{\mathrm{IL}}}{\mathrm{V}_{\mathrm{f}, 0}+\mathrm{V}_{\mathrm{Al}, 0}}-1
$$

where $\mathrm{V}_{\mathrm{f}}, \mathrm{V}_{\mathrm{Al}}, \mathrm{V}_{\mathrm{IL}}$ are $\mathrm{U}-\mathrm{Mo}$ volume, $\mathrm{Al}$ matrix volume, and IL volume, respectively. The suffix 0 indicates pre-irradiation values. The details for how to calculate Eq.(34) are available elsewhere [18].

\subsection{Solution method}

For the unit cell at the given time step, a finite time interval, $\Delta t$, is set. For this time interval, the calculations are performed following the procedure described below.

1) Divide the U-Mo particle into 50 concentric spherical shells that have the same volume.

2) Calculate fission density by using the power history and $\Delta t$.

3) Calculate IL thickness using the model available in [7].

4) Calculate the consumed fuel volume by using the model [7].

5) Update the U-Mo size from the U-Mo size from the previous time step. 
6) Update the IL volume to include the newly formed IL.

7) Update the distance from fuel particle surface to the IL-pore interface (d shown in Fig. 4).

8) Calculate the amount of fission gas production in each shell from the U-Mo fuel particle center to the outer surface of the IL.

9) Update $a_{\mathrm{p}}$ in Eq. (12) from the previous time step for pore growth.

10) Calculate the amount of the released fission gas to the pore from the outer spherical shells in U-Mo by recoil using Eq. (5). In this step, the updated d determined in step 8) is compared with the recoil range in U-Mo.

11) Calculate the amount of fission gas release to the IL from the rest of the spherical shells in U-Mo by recoil using Eq. (5).

12) Calculate the amount of fission gas release to the IL from the U-Mo by diffusion using Eq. (6).

13) Calculate the amount of released fission gas to the pore by recoil and by diffusion through the IL, using Eq. (5) and Eq. (6), respectively. In this step, information for d obtained in step 8) is used.

14) Update the available fission gas retention for each shell using the released fission gas from step 11) and 12).

15) Calculate the cumulative amount of released fission gas to the pore summing the results from step 11) and 12).

16) Calculate $r_{I L}$ using Eq. (32). 
17) Calculate pore volume $V_{p}$.

18) Calculate the volume expansion in the unit cell using Eq. (34) using the model in [18].

19) Calculate porosity in the unit cell.

20) Move to the next time step.

\subsection{Model parameters}

The determination of two constants for utilization in the model, A and $\alpha$ are discussed in the following sections. Because limited data is available in the literature for this fuel form, the values had to be determined through fitting experimental observations.

6.3.1 Constant A for fission induced diffusion in Eq. (8)

For U self-diffusion in $\mathrm{UO}_{2}$, A was given $1.2 \times 10^{-29} \mathrm{~cm}^{5}$ [39]. Olander [49] proposed an order of magnitude lower value $1.5 \times 10^{-30}$ for Xe diffusion in $\mathrm{UO}_{2}$ following Turnbull's $\sim 10^{-30}$ [38]. For the metallic fuel dealt with here, no data were available. Hence, A for U-Mo was determined from a data fit, keeping A slightly lower than that for $\mathrm{UO}_{2}$, noting that the metallic fuel has higher thermal conductivity than $\mathrm{UO}_{2}$. The higher the thermal conductivity, the lower FID is expected to be due to the lower damage incurred by fission [39].

In this work, the best fit was found when the diffusivity constant for U-Mo in Eq. (9) $\mathrm{A}^{U-M o}=2.0 \times 10^{-31}$ and that for IL in Eq. (11) $\mathrm{A}^{I L}=4.5 \times 10^{-28} \mathrm{~cm}^{5}$, where the fission rate was in 
$\mathrm{cm}^{-3} \mathrm{~s}^{-1}$. The prediction results using these FID values for porosity are compared to the measured data in Table 4.

6.3.2 Reduction factor $\alpha$ in Eq. (20)

The contact angles, $\theta_{I L}$ and $\theta_{A l}$, can be calculated analytically using Eqs. (15) and (16), assuming that the IL remains crystalline during irradiation. In this case the reduction factor, $\alpha$, in Eq. (20) is equal to unity, for which the calculated values are $\theta_{I L}=28.5$ degrees and $\theta_{A l}=25.0$ degrees. This result is in accord with the PIE observations. However, as mentioned in the previous section, pores grew to be more concave toward the IL than toward the Al matrix, which is believed to be due to the lowered surface energy of IL caused by irradiation-induced amorphization.

The contact angles at the IL-pore and Al-pore interfaces were measured from optical images from PIE of several plates that showed extensive IL growth. Pores selected for measurement of the contact angles had a lenticular, or crescent, shape at the IL-Al interfaces, with higher convexity at the IL-pore interface. The measurement was performed at the two vertexes of the pore as shown in Fig. 7(b). The measurement results are summarized in Table 4.

During pore growth, these contact angles showed no discernable changes. Hence, the average values of 33.1 degrees for $\theta_{I L}$ and 18.3 degrees for $\theta_{A l}$ were used for the present model. By satisfying the force balance required by Eq. (16), and applying Eqs. (15) and (19), the value of $\alpha$ was determined to be 0.647 . 
6.4 Model prediction results

The measured porosities at several locations near the end of the fuel meat were compared with the predicted values, as illustrated in Fig. 8. A fair agreement is noted for plates V6022M and V6019G. However, considerable underpredictions for plate R3R108 were also found. The possible reason for this inconsistency for the latter plate may be the occurrence of cleavage ruptures in the Al matrix, discussed in section 2. The pore-like cavities caused by the ruptures were likely included in the porosity measurement, resulting in artificially elevated porosity. The ruptures in R3R108 were predicted in an ABAQUS FEA simulation study in which the stress buildup in the Al matrix exceeded the failure strength, and low IL growth created a low-creep condition so that the stresses could not be relieved [50]. Taking this uncertainty into account, the accuracy of the model appears to be acceptable.

\section{Model validation}

The data used for fitting the model parameters were collected from reduced-sized fuel plates. Hence, it was necessary to examine the validity of the present model for full-sized fuel plates. To this end, the model was employed to predict porosities of two full-sized plates from the AFIP-1 test $[51],[52]$. 
The AFIP-1 test irradiated two full-sized plates (1T2 and 1B5) (see Table 5). The plate and meat dimensions are $571 \mathrm{~mm} \times 58 \mathrm{~mm} \times 1.3 \mathrm{~mm}$ and $526 \mathrm{~mm}$ x $43 \mathrm{~mm}$ x $0.51 \mathrm{~mm}$, respectively. The two plates were welded together axially (in the length direction) at their plate bottom ends, and loaded in a coolant channel. Therefore, the total length of the combined plates was about 1142 $\mathrm{mm}$. The conjoined plane was loaded at the axial center of the reactor core. Hence, the fuel bottom end of both plates achieved the peak burnups. The plates were loaded in the ATR flux trap, so the transverse power peaking was less than that of the reduced-size plates. The fuel temperatures were higher for the full size plates than the miniplate tests because of the increased power and the longer heating length. In particular, the temperatures in the bottom plate (1B5) were high because of the downward coolant flow. The life-averaged temperatures were estimated to be $\sim 170{ }^{\circ} \mathrm{C}$ for the top plate (1T2) and $\sim 180{ }^{\circ} \mathrm{C}$ for the bottom plate (1B5) at their respective peak power locations. The extensive IL growth observed in both plates, even with Si-modified Al matrixes, was attributed to the high temperatures at the peak power locations.

After the irradiation, the two plates were separated at the weld-joint. Metallography during PIE was performed at two axial locations, and chemical burnup measurements were performed at nearby locations. For both plates, porosity was measured using optical micrographs and the results are given in Table 5. It turned out that $1 \mathrm{~T} 2$ has greater porosity than 1B5. Considering the higher burnups and higher temperatures for the latter plate, these data suggested that the higher Si content added in 1B5 effectively improved performance [7]. 
Porosity was predicted using the model at the PIE locations and are compared with the measured values in Table 5. For both plates, the predictions were found to be consistent with the measured data. This result demonstrates that the model developed here is also applicable to full-sized plates.

\section{Discussion and conclusions}

The model developed in this study to predict pore growth (and ultimately the porosity increase) in $\mathrm{U}-\mathrm{Mo} / \mathrm{Al}$ dispersion fuel relies on the Young-Laplace equation. This equation is based on balancing the force on the surface of a pore between the pore internal pressure, the stress exerted on the pore surface, and the pore surface tension.

The pore internal pressure is determined by fission gas release from both the U-Mo and the interaction layer (IL) to the pore. The volume of released fission gas is determined by the amount of fission gas generated, which is a function of fission density (or burnup) in the U-Mo and the IL, and by the gas release mechanisms.

Two types of release mechanisms were considered: the recoil mechanism and the diffusion mechanism. The recoil mechanism is dependent upon the size of the U-Mo particles and the recoil ranges of the fission gases. The former is fixed once the fuel is produced, and the latter is a material property, and known in the literature. The diffusion mechanism, as described by the Booth model, is a function of the fission gas diffusivity, the grain size of the diffusing medium, and time. Because the temperature of the diffusing medium is so low, thermal diffusion is 
effectively inactive, so only fission induced diffusion is considered. Therefore, the diffusivity is a function of the fission rate in the diffusion medium. Because PIE observations indicated that the IL has much higher diffusivity, and its retention capacity for fission gas is lower than the U-Mo, its growth enhances fission gas release.

The stress term in the Young-Laplace equation used to determine porosity behavior, implies that the reactor coolant pressure suppresses pore growth. In addition, whether the pore growth kinetics is augmented or restricted is reflected by the evolution of stress states in the fuel meat. An ABAQUS FEA simulation showed that the stress changed to a considerable extent in both magnitude and sign, which can alter the pore growth kinetics.

Pore surface tension also affects pore growth kinetics. Because the pore forms either in the IL or at the IL-Al interface, the surface tension of the IL plays an important role. Because it is amorphous, the IL has low surface tension that facilitates pore growth, suggesting that IL growth is detrimental for fuel performance.

The detrimental effect of IL growth was manifested in the model. The more the IL grows, the more fission gas release to pores occurs. The IL growth also increases fuel meat swelling, which generates a stress condition at locations away from the fuel meat ends that promotes pore growth. In addition, the thicker IL also provides more room for pore growth because it is amorphous and easily deformable. In this context, the recent effort to suppress IL growth by applying a coating on the U-Mo particle appears to be reasonable. 
Some numerical data that were necessary for the model, but are unavailable in the literature, were obtained by a data fit of the PIE data. This numerical data includes the following:

- The diffusivity constant for U-Mo used in Eq. (9) $\left(\mathrm{D}^{U-M o}=\mathrm{A}^{U-M o} \dot{\mathrm{F}}_{\mathrm{f}}\right), \mathrm{A}^{U-M o}=2.0 \times 10^{-31}$ $\mathrm{cm}^{5}$ and that for IL used in Eq. (10) $\left(\mathrm{D}^{I L}=\mathrm{A}^{I L} \dot{\mathrm{F}}_{I L}\right), \mathrm{A}^{I L}=4.5 \times 10^{-28} \mathrm{~cm}^{5}$, where the fission rate is in $\mathrm{cm}^{-3} \mathrm{~s}^{-1}$.

- The reduction in surface energy of the IL due to amorphization during irradiation was fitted using PIE data. As a result, the reduction factor used in Eq. (20) was obtained to be 0.647 , meaning that the surface energy of the IL is $64.7 \%$ of that when the IL is crystalline.

The model in this study is novel in the sense that a reasonably complete picture consisting of the formation and growth of pores based on analytically derived expressions was developed. Furthermore, analytical expressions are provided using mostly known materials properties for the related entities in the fuel system, and a few derived model parameters fitted to observations from in-pile tests. The consistent results of the model calculations with the measured data from independent and more complex full-sized plates demonstrated the versatility of the model.

Although the model has been developed for uncoated U-Mo particles, it is considered to be applicable to coated U-Mo fuel provided the IL growth kinetics is known for this fuel, because all other mechanisms in the model are also applicable for the coated U-Mo fuel. 


\section{Acknowledgments}

This study used information gathered from three reduced-size plates from RERTR-4, -5, and -9 tests and two full-size plates from AFIP-1 test irradiated at the ATR. For the former three reduced-size plates, the authors acknowledge Drs. S. Hayes and M. Meyer from INL and G. Hofman from ANL for the irradiation test designs, Mr. T. Wiencek from ANL for the test plate fabrication, and late Dr. R. Strain from ANL for PIEs. For the latter full-size plates, Mr. A. Robinson and Dr. D. Wachs are recognized. The operations staff at the ATR is also acknowledged for these irradiation tests. The physics data available by Dr. G. Chang and Ms. M. Lillo are also appreciated. The authors wish to thank Drs. A. Leenaers and P. Lemoine for the FUTURE test PIE images available in the literature that were used to obtain data in Table 4. This work was supported by the U.S. Department of Energy, National Nuclear Security Administration (NNSA), Office of Material Management and Minimization (NA-23) Reactor Conversion Program under Contract No. DE-AC-02-06CH11357 between UChicago Argonne, LLC and the US Department of Energy, and in part by the National Research Foundation of Korea (NRF) grant funded by the Korean government (Ministry of Education, Science and Technology) under contract number 2011-0031771.

\section{References}

[1] G.L. Hofman, Yeon Soo Kim, M.R. Finlay, J.L. Snelgrove et al., Proc. Internat. Mtg. Reduced Enrichment for Research and Test Reactors (RERTR), Chicago, IL, USA, Oct. 5-10, 2003. Available on the web http://www.rertr.anl.gov

[2] P. Lemoine, J.L. Snelgrove, N. Arkhangelsky, L. Alvarez, Trans. Internat. Topical Meeting Research Reactor Fuel Management (RRFM), Munich, Germany, Mar. 21-24, 2004. Available on the web http://www.euronuclear.org/meetings/rrfm2004/index.htm

[3] A. Leenaers, S. Van den Berghe, E. Koonen, C. Jarousse, F. Huet, M. Trotabas, M. Boyard, S. Guillot, L. Sannen, M. Verwerft., J. Nucl. Mater., 335 (2004) 39.

[4] O.A. Golosov, S.A. Averin, V.L. Panchenko, M.S. Lyutikova, Trans. Internat. Topical Meeting Research Reactor Fuel Management (RRFM), Vienna, Austria, Mar. 22-25, 2009. Available on the web http://www.euronuclear.org/meetings/rrfm2004/index.htm 
[5] Yeon Soo Kim, G.L. Hofman, J. Nucl. Mater. 419 (2011) 291.

[6] S. Hu, A.M. Casella, C.A. Lavender, D.J. Senor, D.E. Burkes, J. Nucl. Mater., 462 (2015) 64.

[7] Yeon Soo Kim, G.L. Hofman, A.B. Robinson, D.M. Wachs, Nucl. Technol. 184 (2013) 42.

[8] J. Allenou, H. Palancher, X. Iltis, M. Cornen, O. Tougait, R. Tucoulou, E. Welcomme, Ph. Martin, C. Valot, F. Charollais, M.C. Anselmet, P. Lemoine, J. Nucl. Mater., 399 (2010) 189.

[9] S. Van den Berghe et al., Adv. Sci. Technol. 73 (2010) 78.

[10] A. Leenaers, S. Van den Berghe, C. Detavernier, J. Nucl. Mater. 440 (2013) 220.

[11] A. Leenaers, S. Van den Berghe, E. Koonen, V. Kuzminov, C. Detavernier, J. Nucl. Mater. 458 (2015) 380.

[12] Yeon Soo Kim, J.M. Park, K.H. Lee, B.O. Yoo, H.J. Ryu, B. Ye, J. Nucl. Mater. 454 (2014) 238.

[13] H.J. Ryu, Yeon Soo Kim, Nucl. Eng. Technol. 46 (2014) 159.

[14] J.-Y. Oh, Yeon Soo Kim, Y.-W. Tahk, H.-J. Kim, E.-H. Kong, J.-S. Yim, J. Nucl. Mater. submitted (2015).

[15] G.L. Hofman, Yeon Soo Kim, Presentation at RERTR 2014 Meeting, Unpublished study, 2014.

[16] Yeon Soo Kim, Uranium Intermetallic Fuels (U-Al, U-Si, U-Mo), In: Comprehensive Nuclear Materials, R.J.M. Konings, (ed.), volume 3, p 391-422, Amsterdam, Elsevier (2012).

[17] K. Farrell, Performance of Aluminum in Research Reactors. In: Konings R.J.M., (ed.) Comprehensive Nuclear Materials, volume 5, pp. 143-175 Amsterdam: Elsevier (2012). 
[18] Yeon Soo Kim, G.Y. Jeong, J.M. Park, A.B. Robinson, J. Nucl. Mater. 465 (2015) 142.

[19] Yeon Soo Kim, G.L. Hofman, J. Nucl. Mater. 425 (2012) 181.

[20] G.Y. Jeong, Yeon Soo Kim, D. Sohn, J. Nucl. Mater. 466 (2015) 509.

[21] T. Wiencek, Standard fabrication method of fuel plates, ANL/RERTR/TM-15, Argonne National Laboratory, 1995.

[22] J.M. Park, KAERI, Korea, private communication, 2016.

[23] H.J. Ryu, Y.S. Kim, G.L. Hofman, J. Nucl. Mater. 385 (2009) 623.

[24] S. Van den Berghe, W. Van Renterghem, A. Leenaers, J. Nucl. Mater. 375 (2008) 340.

[25] O.A. Golosov, V.B. Semerikov, S.H. Boganov, M.S. Lyutikova, in: Proc. Internat. Mtg. on Reduced Enrichment for Research and Test Reactors (RERTR), Prague, Czech Republic, September 23-27, 2007. <http://www.rertr.anl.gov/index.html>.

[26] J. Gan, D.D. Keiser, D.M. Wachs, A.B. Robinson, B.D. Miller, T.R. Allen, J. Nucl. Mater. 396 (2010) 234.

[27] A. Leenaers, S. Van den Berghe, E. Koonen et al., J. Nucl. Mater. 335 (2004) 39.

[28] S. Van den Berghe, P. Lemoine, Nucl. Eng. Technol. 46 (2014) 125.

[29] A. Leenaers, S. Van den Berghe, E. Koonen et al., J. Nucl. Mater. 458 (2015) 380.

[30] J.M. Hamy, P. Lemoine, F. Huet, B. Guigon, C. Jarousse, J.L. Emin, Trans. Intern. Topical Mtg. on Research Reactor Fuel Management (RRFM), Mar. 21-24, 2004, Munchen, Germany. Available at http://www.euronuclear.org/meetings/rrfm2008/index.htm

[31] J.W. Prados, J.L. Scott, Models for fission-gas release from coated fuel particles, Oak Ridge National Laboratory report, ORNL-3421, 1963. 
[32] Yeon Soo Kim, G.L. Hofman, H.J. Ryu, J.M. Park, A.B. Robinson, D.M. Wachs, Nucl. Eng. Technol. 45 (2013) 827.

[33] D.R. Olander, Fundamental aspects of nuclear reactor fuel elements, TID-26711-P1, US Dept. of Commerce, 1976.

[34] A.H. Booth, A Method of Calculating Fission-Gas Diffusion from UO2 and Its Application to the X-2-f Loop Test, AECL Chalk River Report, CRDC-721, 1957.

[35] C.K. Kim, J.M. Park, H.J. Ryu, Nucl. Eng. Technol., 39 (2007) 617.

[36] Yeon Soo Kim, G.L. Hofman, J.S. Cheon, J. Nucl. Mater. 436 (2013) 14.

[37] M.A. Mansouri, D.R. Olander, J. Nucl. Mater. 254 (1998) 22.

[38] J.A. Turnbull, C.A. Friskney, J.R. Findlay, F.A. Johnson, A.J. Walter, J. Nucl. Mater. 107 (1982) 168.

[39] Hj. Matzke, Rad. Eff. 75 (1983) 317.

[40] Yeon Soo Kim, G.Y. Jeong, ANL/GTRI/TM-14/17, Argonne National Laboratory, Nov. 2014.

[41] G.Y. Jeong, Yeon Soo Kim, D.S. Sohn, Trans. Am. Nucl. Soc., New Orleans, LA, June $12-16,2016$.

[42] L. A. Girifalco, R. J. Good, J. Phys. Chem., 61 (1957) 904.

[43] D.H. Buckley, J. Ferrante, Maters. Sci. Eng. 83 (1986) 177

[44] S. Popel, V. Pavlov, in: S.N. Zadumkin (Ed.), The Physical Chemistry of Surface Phenomena at High Temperatures, Nauk. Dumka, Kiev, 1977.

[45] S. Blonski, S. H. Garofalini, Surf. Sci. 295, (1993) 263.

[46] G.F. Ma et al, J. Alloys Compd., 456 (2008) 379. 
[47] B. Ye, J. Rest, Yeon Soo Kim, G.L. Hofman, Nucl. Technol., 191 (2015) 27.

[48] W.R. Tyson, Surf. Sci., 62 (1977) 267.

[49] D. Olander, J. Nucl. Mater. 372 (2008) 94.

[50] G.Y. Jeong, Yeon Soo Kim, G.H. Lee, D.S. Sohn, Trans. ANS meeting, New Orleans, LA, Jun. $12-18,2016$.

[51] A.B. Robinson, Proc. Int. Mtg. Reduced Enrichment for Research and Test Reactors (RERTR), October 10-14, 2010; http:www.rertr.anl.gov.

[52] D.M. Perez, M.A. Lillo, G.S. Chang, G.A. Roth, N.E. Woolstenhulme, D.M. Wachs, AFIP-1 Irradiation summary report, INL/EXT-11-22045, Idaho National laboratory, 2011. 


\section{Nomenclature}

$\mathrm{HEU}=$ highly enriched uranium

LEU $=$ low enriched uranium

$\mathrm{FD}=$ fission density

$\mathrm{PIE}=$ post irradiation examination

$\mathrm{ATR}=$ advanced test reactor

$\mathrm{EOL}=$ end of life

$\mathrm{U}-\mathrm{Mo}=$ fuel kernel made of uranium alloyed with Mo

$\mathrm{IL}=$ interaction layer

$\mu=$ fission fragment recoil range

$\beta_{U-M o}=$ amount of fission gas generated per FIHMA in the unit volume of U-Mo

$\beta_{I L}=$ amount of fission gas generated per FIHMA in the unit volume of IL

$y_{X e}=$ Xe fission yield

$y_{K r}=\mathrm{Kr}$ fission yield

$F_{d}^{\mathrm{U}-\mathrm{Mo}}=$ fission density in U-Mo

$\rho_{U-M o}=$ physical density of U-Mo

$\rho_{I L}=$ physical density of IL

$\mathrm{M}=$ molecular weight 
$\mathrm{N}_{\mathrm{A}}=$ Avogadro's number

$\mathrm{R}=$ fuel particle radius

$\mathrm{i}=$ material index $(\mathrm{U}-\mathrm{Mo}, \mathrm{IL})$.

$d=$ distance from fuel particle surface to IL-pore interface

$P_{e}=$ escape probability of fission gas from the fuel particle inside to outside

$R_{f}=$ amount of fission gas released from the fuel particle by fission induced recoil per FIHMA

$R_{d}=$ amount of fission gas released from the fissioning solid by diffusion per FIHMA

$V_{f}=$ volume of the body where fission occurs

$\mathrm{V}_{\mathrm{c}}=$ volume of the unit cell used for the model

$\mathrm{a}=$ equivalent sphere radius in the Booth diffusion model

$\mathrm{D}=$ fission induced diffusion coefficient of fission gas

$A=$ constant for fission induced diffusion coefficient

$\dot{\mathrm{F}}=$ fission density rate or fission rate

$\mathrm{t}=$ time

$\mathrm{Y}=\mathrm{IL}$ thickness

$r_{I L}=$ radius of curvature for the IL-pore interface

$r_{A l}=$ radius of curvature for the Al-pore interface

$r_{p}=$ pore radius 
$a_{\mathrm{p}}=$ ratio of the cross-sectional area of the pore to the IL surface area (see Eq. (12))

$\mathrm{P}=$ pore pressure

$\sigma=$ stress at the surface of the pore

$\theta_{A l}=$ contact angle at the $\mathrm{Al}$ matrix and pore interface

$\theta_{I L}=$ contact angle at the IL and pore interface

$\gamma_{A l}=$ surface energy of Al metal

$\gamma_{I L}=$ surface energy of IL

$\gamma_{\mathrm{IL} / \mathrm{Al}}=$ interfacial energy at the IL-Al interface

$\phi=$ constant used for Eq. (17)

$\mathrm{H}=1 / r_{I L}$

$\mathrm{x}=$ atom fraction of $\mathrm{Al}$ or $\mathrm{U}-\mathrm{Mo}$ in the $\mathrm{IL}$

$\alpha=$ reduction factor for the surface tension of the amorphous IL from the crystalline state

$\mathrm{T}=$ temperature in the pore

$\mathrm{k}=$ Boltzmann's constant

$\zeta=$ porosity in the meat 
$\underline{\text { Table captions }}$

Table 1 Irradiation data for the miniplates used for modeling

Table 2 Surface energies and interfacial energies used for the study

Table 3 Obtained fission induced diffusion coefficients (in Eq.(9) and Eq.(10)) and comparison between the predicted and measured porosities

Table 4 Measured contact angles at IL-pore interface $\left(\theta_{I L}\right)$ and Al-pore interface $\left(\theta_{A l}\right)$ (see Fig. 7)

Table 5 AFIP-1 test data and measured porosity data

Figure captions

Fig. 1 Post-irradiation images of $\mathrm{V6022M}$ at with fission density of $5.5 \times 10^{21} \mathrm{f} / \mathrm{cm}^{3}$. Note the difference in the scale markers. The darkest spots in the SEM image are fission gas bubbles.

Fig. 2 OM images of fuel meat cross sections of the plates used for model development. The red boxes show regions where pores were formed.

Fig. 3 Porosity data for V6022M, V6019G and R3R108 measured every $0.5 \mathrm{~mm}$ from the meat end in the width direction.

Fig. 4 Schematics explaining the model for fission gas release to a pore. 
Fig. 5 Schematic showing force balance on the pore surface.

Fig. 6 Evolution of hydrostatic stress calculated for V6022M, V6019G and R3R108. A positive stress indicates a compressive stress state and vice versa.

Fig. 7 Schematics showing (a) the unit cell model composed of a U-Mo particle, IL on the U-Mo, a pore at the IL-Al interface, and the corresponding Al matrix, (b) the details of the geometrical configuration around the pore. The numbers 1 and 2 stand for vertexes labeled in Table 4.

Fig. 8 Comparison between measured and predicted porosities for V6022M, V6019G and R3R108 at the meat end region. 
Table 1 Irradiation data for the miniplates

\begin{tabular}{|c|c|c|c|c|c|c|c|c|}
\hline $\begin{array}{c}\text { In-pile } \\
\text { test ID }\end{array}$ & Plate ID & $\begin{array}{c}\text { U- } \\
\text { density } \\
(\mathrm{g}- \\
\left.\mathrm{U} / \mathrm{cm}^{3}\right)\end{array}$ & $\begin{array}{c}\text { Fuel } \\
\text { type }\end{array}$ & $\begin{array}{c}\text { Matrix } \\
\text { type }\end{array}$ & $\begin{array}{c}\text { Particle } \\
\text { size } \\
(\mu \mathrm{m})\end{array}$ & $\begin{array}{c}\text { Irradiation } \\
\text { time } \\
(\mathrm{EFPD})\end{array}$ & $\begin{array}{c}\text { FD at } \\
\text { meat } \\
\text { center } \\
\left(10^{21}\right. \\
\left.\mathrm{f} / \mathrm{cm}^{3}\right)\end{array}$ & $\begin{array}{c}\text { Average } \\
\text { FD } \\
\text { between } \\
\text { meat end } \\
\text { and 5 } \\
\mathrm{mm} \text { to } \\
\text { center } \\
\left(10^{21}\right. \\
\left.\mathrm{f} / \mathrm{cm}^{3}\right)\end{array}$ \\
\hline $\begin{array}{c}\text { RERTR- } \\
4\end{array}$ & V6022M & 6 & $\begin{array}{c}\mathrm{U}- \\
10 \mathrm{Mo}\end{array}$ & $\mathrm{Al}$ & 65 & 257 & 5.2 & 5.8 \\
\hline $\begin{array}{c}\text { RERTR- } \\
5\end{array}$ & $\mathrm{~V} 6019 \mathrm{G}$ & 6 & $\begin{array}{c}\mathrm{U}- \\
10 \mathrm{Mo}\end{array}$ & $\mathrm{Al}$ & 65 & 113 & 2.9 & 3.2 \\
\hline $\begin{array}{c}\text { RERTR- } \\
9\end{array}$ & R3R108 & 8 & $\mathrm{U}-7 \mathrm{Mo}$ & $\mathrm{Al}-5 \mathrm{Si}$ & 50 & 98 & 3.7 & 6.6 \\
\hline
\end{tabular}


Table 2 Surface energies and interfacial energies used for the study

\begin{tabular}{|l|l|l|}
\hline & Surface energy $\left(\mathrm{J} / \mathrm{m}^{2}\right)$ & Ref. \\
\hline U-Mo & 0.5 & {$[47]$} \\
\hline Al & 1.143 & {$[48]$} \\
\hline IL $\left(\mathrm{UMoAl}_{4}\right)$ & 1.014 & $\mathrm{P}$ \\
\hline & Interfacial energy $\left(\mathrm{J} / \mathrm{m}^{2}\right)$ & \\
\hline IL-Al interface & 1.942 & $\mathrm{P}$ \\
\hline
\end{tabular}

p: present study 
Table 3 Obtained fission induced diffusion coefficients (in Eq.(9) and Eq.(10)) and comparison between the predicted and measured porosities

\begin{tabular}{|c|c|c|c|c|c|c|}
\hline & \multirow{2}{*}{$\begin{array}{l}\text { Distance } \\
\text { from } \\
\text { meat } \\
\text { edge } \\
(\mathrm{mm})\end{array}$} & \multirow{2}{*}{$\begin{array}{l}\text { Fission } \\
\text { density in } \\
\text { fuel } \\
\text { particles } \\
\left(10^{21}\right. \\
\left.\text { fission } / \mathrm{cm}^{3}\right)\end{array}$} & \multirow{2}{*}{$\begin{array}{l}D^{U-M o} \\
\left(10^{-17}\right. \\
\left.\mathrm{cm}^{2} / \mathrm{s}\right) \text { in } \\
\text { Eq. (9) }\end{array}$} & \multirow{2}{*}{$\begin{array}{l}D^{I L}\left(10^{-14}\right. \\
\left.\mathrm{cm}^{2} / \mathrm{s}\right) \text { in } \\
\text { Eq. (11) }\end{array}$} & \multicolumn{2}{|c|}{ Porosity at EOL (\%) } \\
\hline & & & & & Measured & Predicted \\
\hline \multirow[t]{9}{*}{ V6022M } & 1.5 & 5.96 & 5.35 & 2.60 & 0.1 & 0.25 \\
\hline & 2.0 & 5.82 & 5.22 & 2.54 & 0.5 & 0.28 \\
\hline & 2.5 & 5.73 & 5.14 & 2.50 & 2.3 & 2.59 \\
\hline & 3.0 & 5.65 & 5.07 & 2.46 & 9.5 & 9.49 \\
\hline & 3.5 & 5.56 & 5.00 & 2.43 & 9.2 & 10.0 \\
\hline & 4.0 & 5.48 & 4.92 & 2.39 & 7.0 & 6.0 \\
\hline & 4.5 & 5.41 & 4.85 & 2.36 & 6.5 & 6.87 \\
\hline & 5.0 & 5.34 & 4.79 & 2.33 & 3.2 & 2.62 \\
\hline & 5.5 & 5.27 & 4.75 & 2.31 & 2.2 & 1.25 \\
\hline \multirow[t]{5}{*}{ V6019G } & 1.5 & 3.10 & 6.46 & 3.08 & 0.8 & 0.06 \\
\hline & 2.0 & 3.02 & 6.20 & 3.01 & 2.1 & 0.91 \\
\hline & 2.5 & 2.98 & 6.10 & 2.97 & 2.2 & 2.01 \\
\hline & 3.0 & 2.94 & 6.01 & 2.92 & 1.7 & 1.31 \\
\hline & 3.5 & 2.89 & 5.92 & 2.88 & 0.9 & 0.74 \\
\hline \multirow[t]{2}{*}{ R3R108 } & 2.0 & 6.32 & 14.9 & 7.26 & 2.6 & 0.96 \\
\hline & 2.5 & 5.63 & 14.1 & 6.85 & 1.5 & 0.38 \\
\hline
\end{tabular}


Table 4 Measured contact angles at IL-pore interface $\left(\theta_{I L}\right)$ and Al-pore interface $\left(\theta_{A l}\right)$ (see Fig. 7)

\begin{tabular}{|c|c|c|c|c|c|c|c|c|c|}
\hline \multirow[b]{2}{*}{$\begin{array}{l}\text { In-pile } \\
\text { test ID }\end{array}$} & \multirow[b]{2}{*}{$\begin{array}{l}\text { Sample } \\
\text { ID }\end{array}$} & \multirow{2}{*}{$\begin{array}{r}\text { Fission } \\
\text { density } \\
\left(10^{21}\right. \\
\left.\mathrm{f} / \mathrm{cm}^{3}\right)\end{array}$} & \multirow[b]{2}{*}{$\begin{array}{c}\text { Temp. } \\
\left({ }^{\circ} \mathrm{C}\right)\end{array}$} & \multirow[b]{2}{*}{$\begin{array}{c}\text { Measurement } \\
\text { location ID }\end{array}$} & \multicolumn{2}{|c|}{ Vertex 1} & \multicolumn{2}{|c|}{ Vertex 2} & \multirow[b]{2}{*}{$\begin{array}{l}\text { Source } \\
\text { Ref. }\end{array}$} \\
\hline & & & & & $\theta_{I L}$ & $\theta_{A l}$ & $\theta_{I L}$ & $\theta_{A l}$ & \\
\hline \multirow[t]{9}{*}{ RERTR4 } & $623 \mathrm{~A}$ & 4.41 & 100 & 1 & 31.0 & 19.7 & 29.1 & 11.6 & $\mathrm{P}$ \\
\hline & $623 \mathrm{~A}$ & 4.41 & & 2 & 41.0 & 16.7 & 36.2 & 21.9 & $\mathrm{P}$ \\
\hline & $623 \mathrm{~A}$ & 4.36 & & 3 & 21.5 & 10.8 & 24.4 & 11.6 & $\mathrm{P}$ \\
\hline & $623 \mathrm{AD}$ & 5.12 & 137 & 4 & 29.9 & 27.5 & 31.0 & 22.3 & $\mathrm{P}$ \\
\hline & $623 \mathrm{AD}$ & 4.96 & & 5 & 39.4 & 21.2 & 37.5 & 19.8 & $\mathrm{P}$ \\
\hline & $623 \mathrm{AD}$ & 4.94 & & 6 & 34.0 & 21.1 & 29.3 & 28.2 & $\mathrm{P}$ \\
\hline & $623 \mathrm{AD}$ & 4.94 & & 7 & 24.0 & 10.3 & 29.4 & 9.8 & $\mathrm{P}$ \\
\hline & $623 \mathrm{AD}$ & 5.24 & & 8 & 35.1 & 12.2 & 41.9 & 14.4 & $\mathrm{P}$ \\
\hline & $623 \mathrm{AD}$ & 5.24 & & 9 & 41.0 & 18.5 & 34.0 & 19.2 & $\mathrm{P}$ \\
\hline RERTR5 & $600 Q$ & 2.78 & 126 & 10 & 26.5 & 15.6 & 30.1 & 22.4 & $\mathrm{P}$ \\
\hline \multirow[t]{3}{*}{ FUTURE } & & 1.41 & 130 & 11 & 31.0 & 10.7 & 39.5 & 12.6 & {$[3]$} \\
\hline & & 1.41 & & 12 & 37.4 & 29.7 & 41.1 & 33.0 & [3] \\
\hline & & 1.41 & & 13 & 33.2 & 16.7 & & & {$[2]$} \\
\hline
\end{tabular}

p: present study 
Table 5 AFIP-1 test data and measured porosity data

\begin{tabular}{|c|c|c|c|c|}
\hline Plate ID & \multicolumn{2}{|l|}{$1 \mathrm{~T} 2$} & \multicolumn{2}{|l|}{$1 \mathrm{~B} 5$} \\
\hline Plate position in the channel & \multicolumn{2}{|l|}{ Upper } & \multicolumn{2}{|l|}{ Lower } \\
\hline $\begin{array}{l}\text { Fuel meat composition } \\
\text { (Fuel alloy/matrix) }\end{array}$ & \multicolumn{2}{|c|}{$\mathrm{U}-7 \mathrm{Mo} / \mathrm{Al}-2 \mathrm{Si}$} & \multicolumn{2}{|c|}{$\mathrm{U}-7 \mathrm{Mo} / \mathrm{Al}-5 \mathrm{Si}$} \\
\hline U-loading (g-U/cm³ -meat) & \multicolumn{2}{|l|}{8} & \multicolumn{2}{|l|}{8} \\
\hline Enrichment (wt.\%U-235) & \multicolumn{2}{|l|}{19.75} & \multicolumn{2}{|l|}{19.75} \\
\hline Average particle U-Mo size $(\mu \mathrm{m})$ & \multicolumn{2}{|l|}{65} & \multicolumn{2}{|l|}{65} \\
\hline Irradiation time (EFPD) & \multicolumn{2}{|l|}{158.2} & \multicolumn{2}{|l|}{158.2} \\
\hline \multirow{2}{*}{ PIE location } & UR-LE & LR-LE & UL-RE & LR-LE \\
\hline & $344 \mathrm{~mm}^{\mathrm{a}}$ & $136 \mathrm{~mm}$ & $344 \mathrm{~mm}$ & $136 \mathrm{~mm}$ \\
\hline Fission density $\left(10^{21} \mathrm{f} / \mathrm{cm}^{3}\right)^{b}$ & 4.4 & 5.7 & 4.8 & 5.8 \\
\hline Measured porosity $(\%)$ & $1.6 \pm 0.2$ & $5.5 \pm 0.3$ & $1.3 \pm 0.1$ & $2.3 \pm 0.2$ \\
\hline Predicted porosity $(\%)$ & 1.7 & 5.3 & 0.9 & 2.8 \\
\hline
\end{tabular}

a: from the bottom end of the plate, $b$ : calculated from the chemical measurement data 


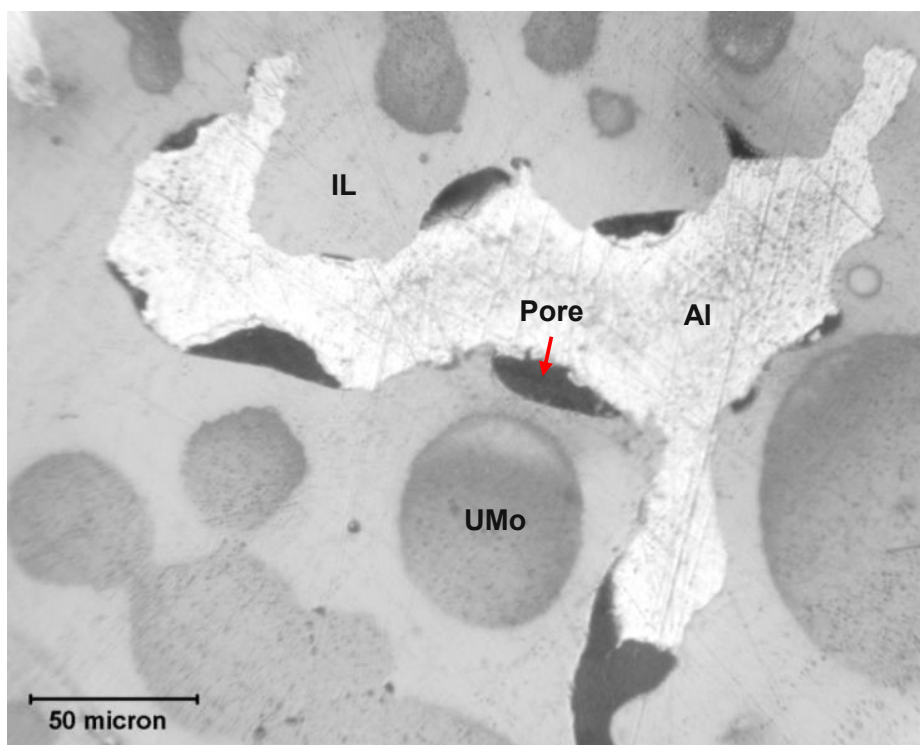

(a) Optical micrograph

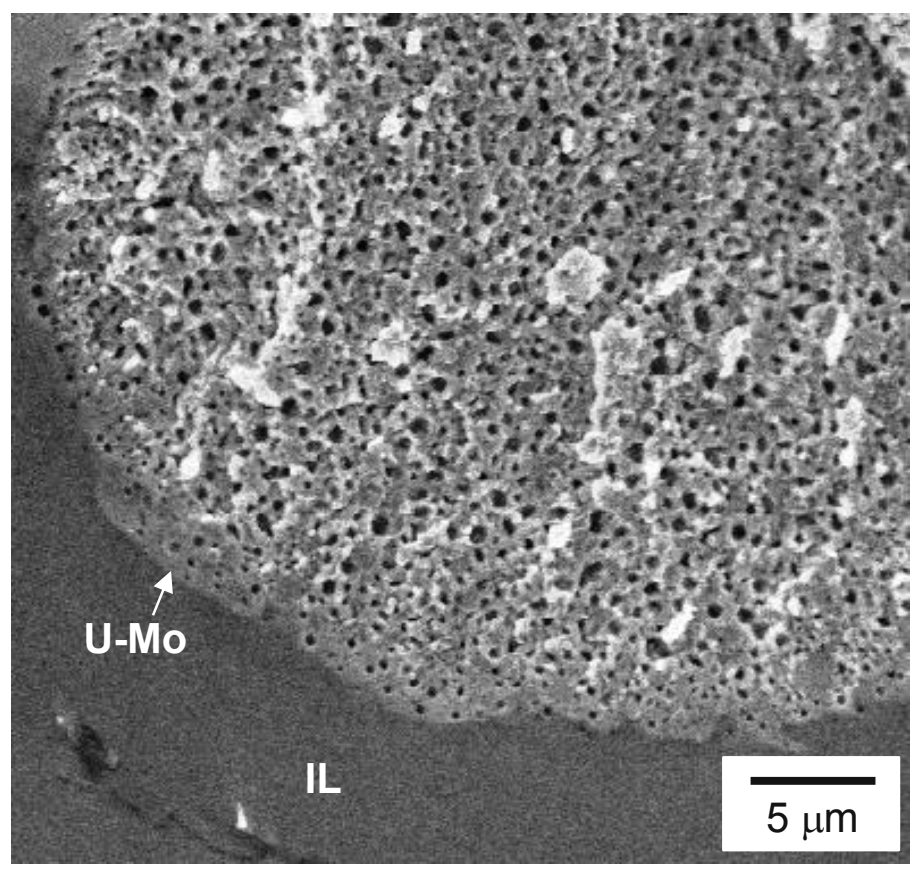

(b) SEM

Fig. 1 Post-irradiation images of V6022M at with fission density of $5.5 \times 10^{21} \mathrm{f} / \mathrm{cm}^{3}$. Note the difference in the scale markers. The darkest spots in the SEM image are fission gas bubbles. Note the substantial morphological differences between the pores that have developed in a) the interaction layer and b) within the fuel particle. 


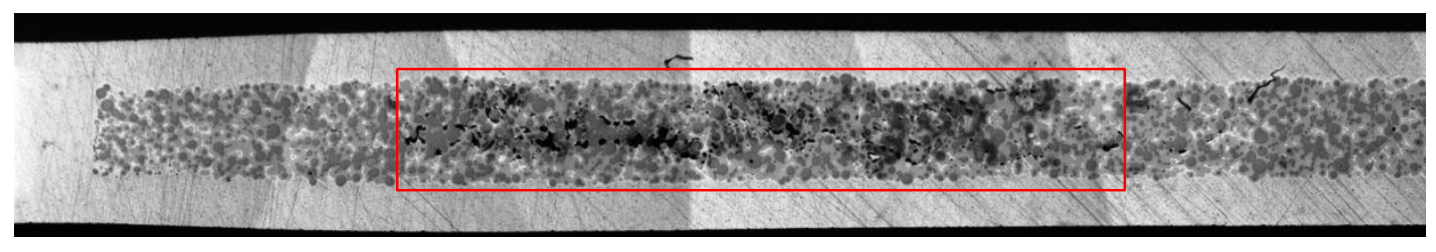

V6022M

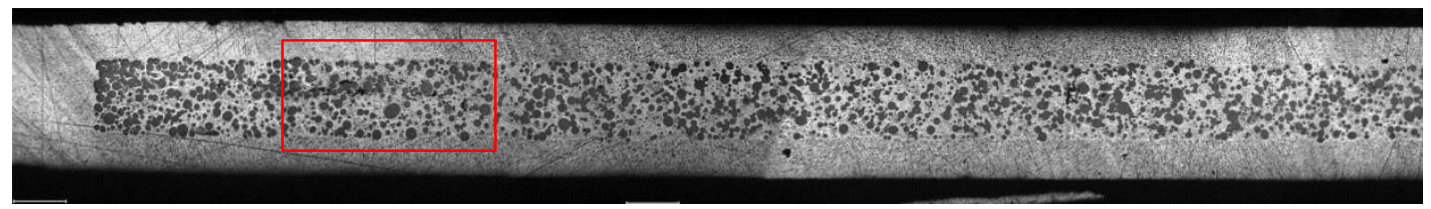

V6019G

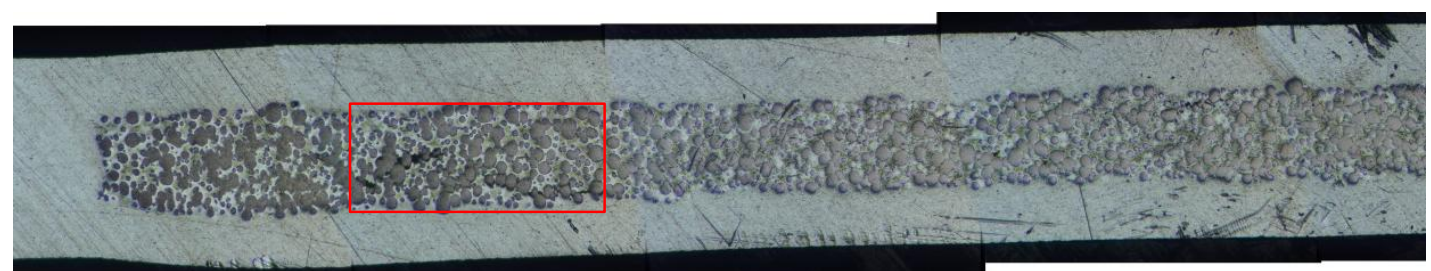

R3R108

Fig. 2 OM images of fuel meat cross sections of the plates used for model development. The red boxes show regions where pores were formed. 


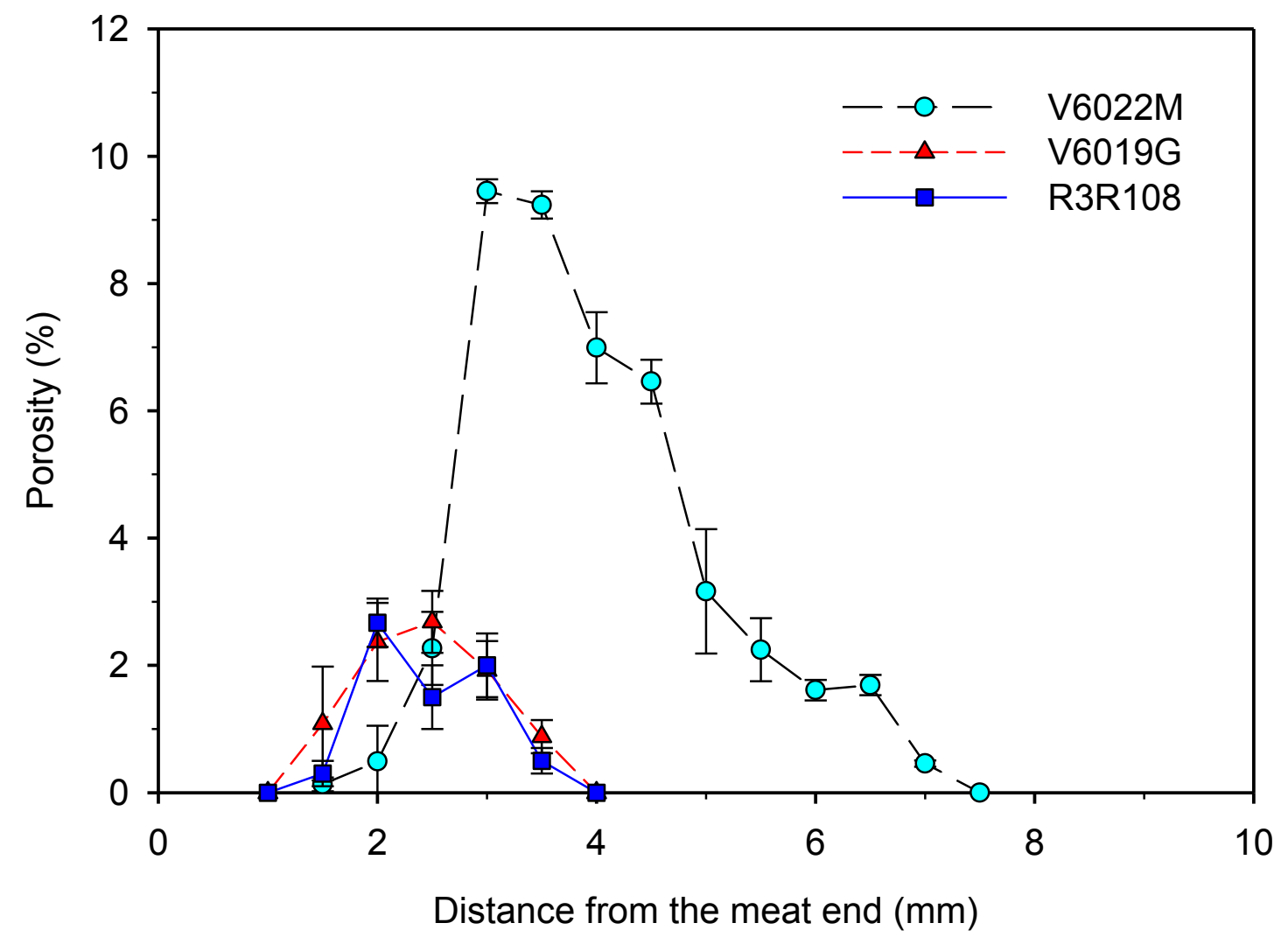

Fig. 3 Porosity data for V6022M, V6019G and R3R108 measured every $0.5 \mathrm{~mm}$ from the meat end in the width direction. 


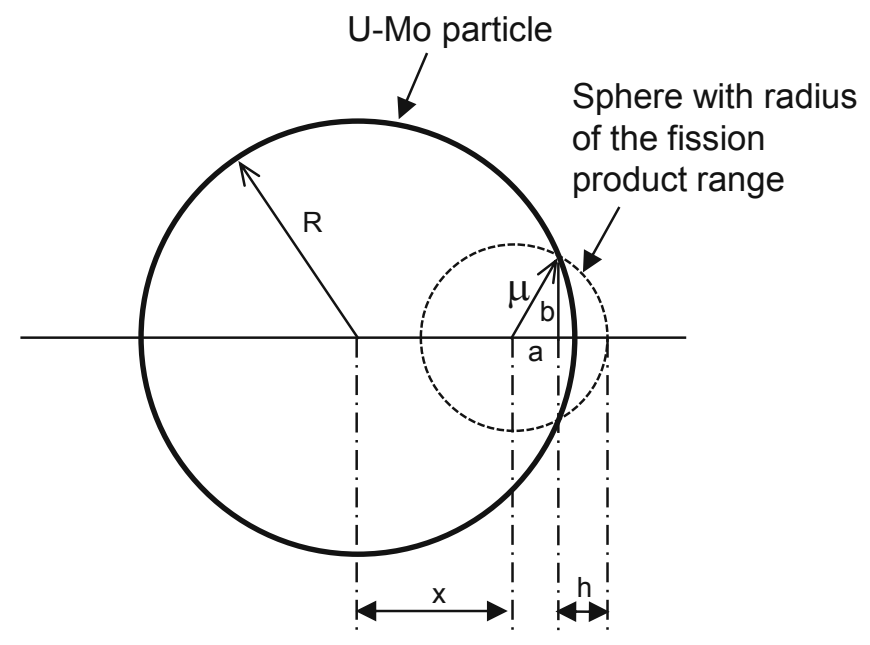

(a) A schematic used to model recoil probability for a fission gas atom from a U-Mo particle
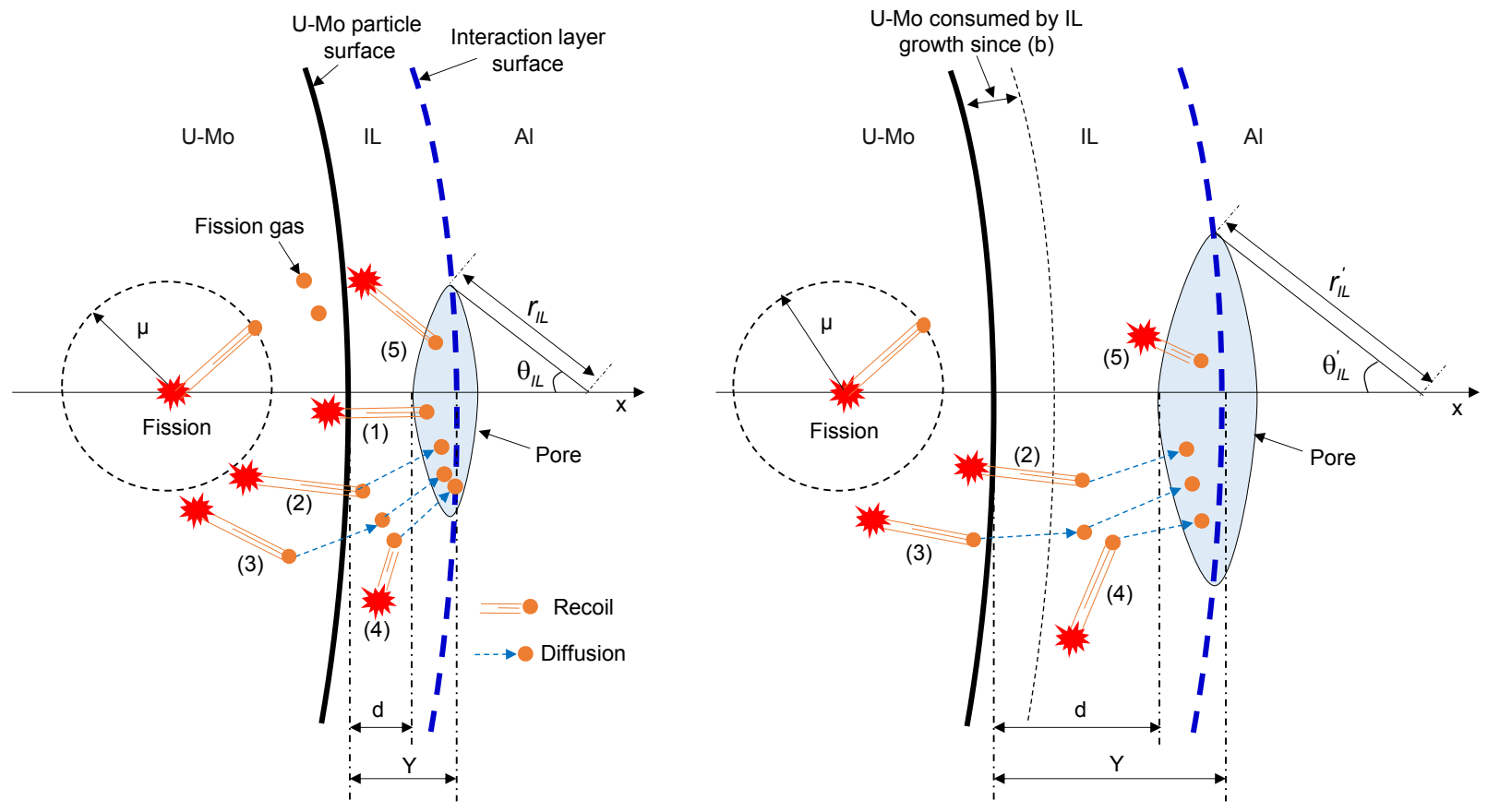

(b) Available fission gas release routes for $\mathrm{d} \leq \mu$

(c) Available fission gas release routes for $\mu$

$<\mathrm{d}$

Fig. 4 Schematics explaining the model for fission gas release to a pore. 


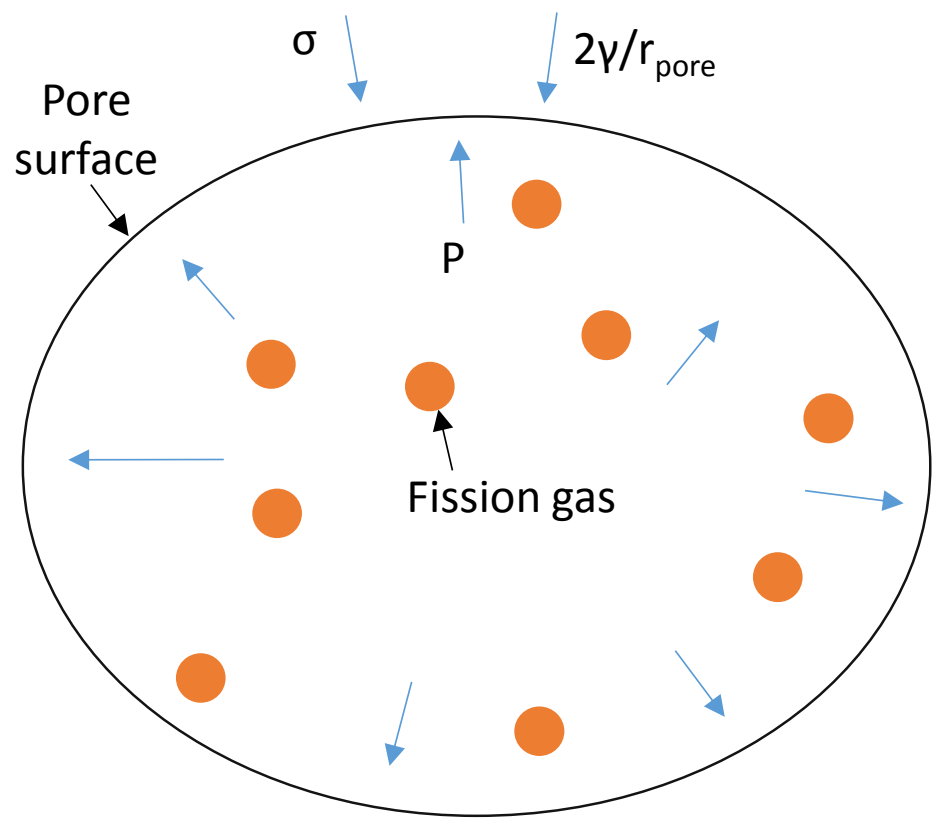

Fig. 5 Schematic showing force balance on the pore surface. 


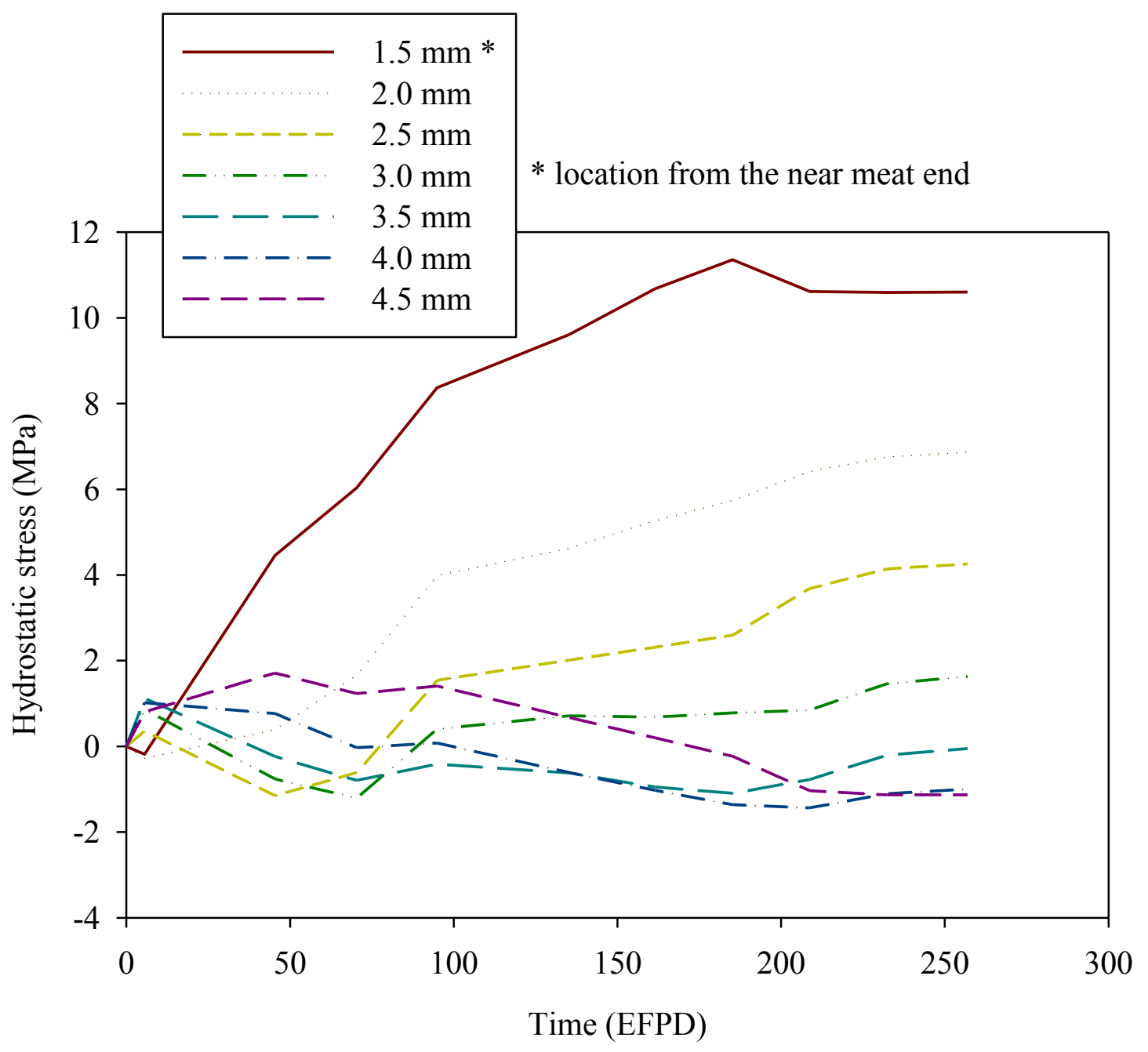

(a) V6022M 


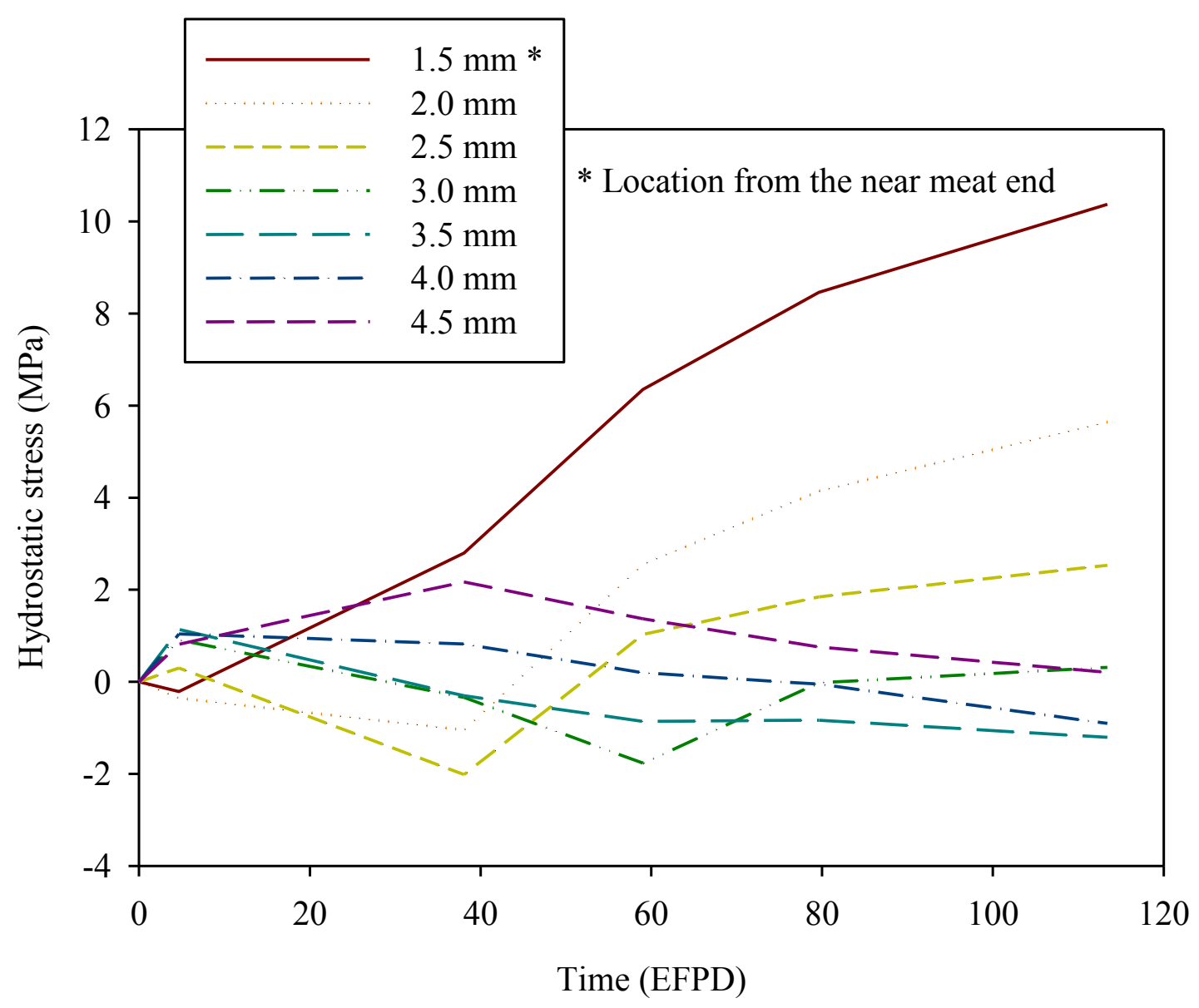

(b) V6019G 


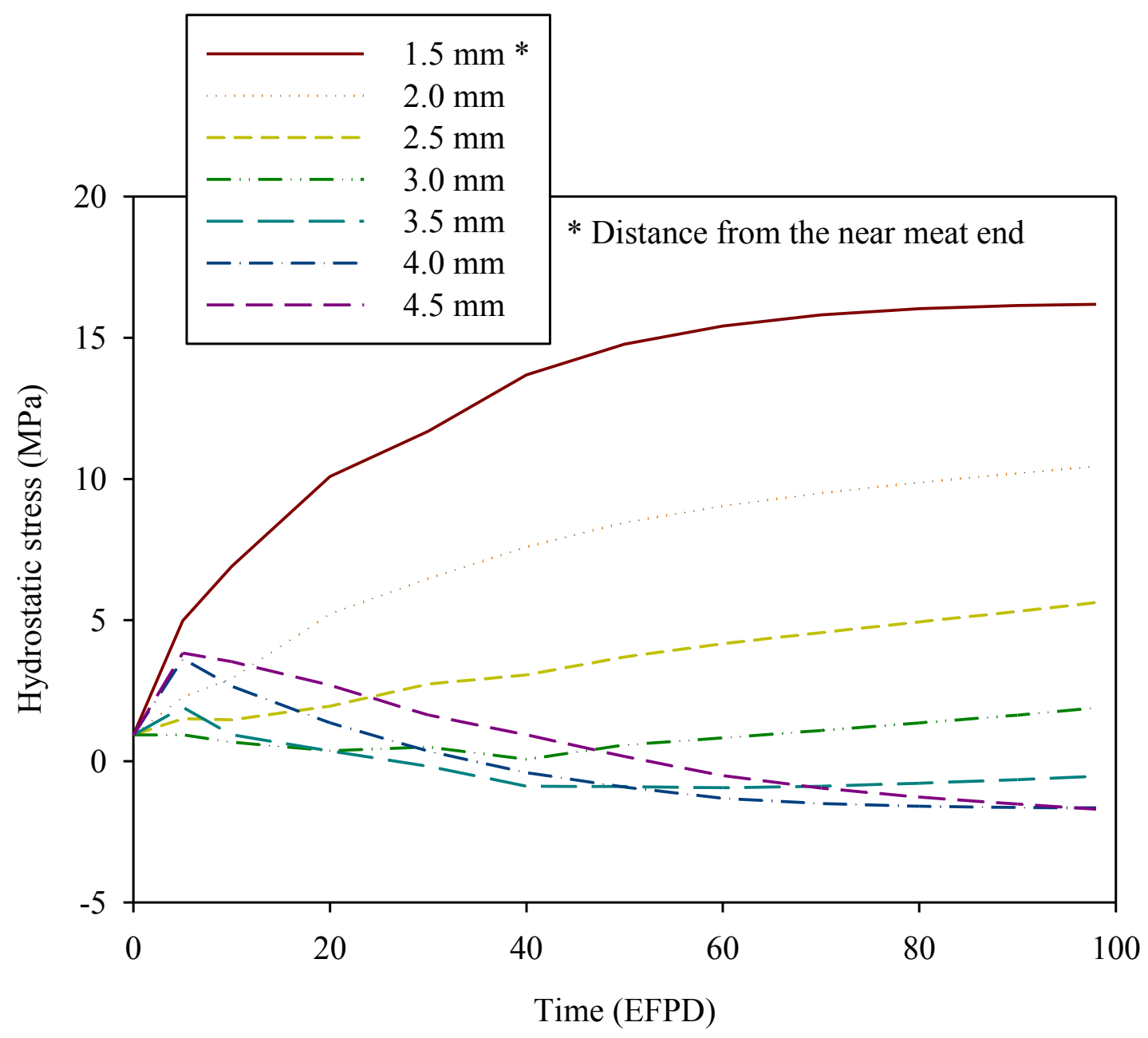

(c) R3R108

Fig. 6 Evolution of hydrostatic stress calculated for V6022M, V6019G and R3R108. A positive stress indicates a compressive stress state and vice versa. 


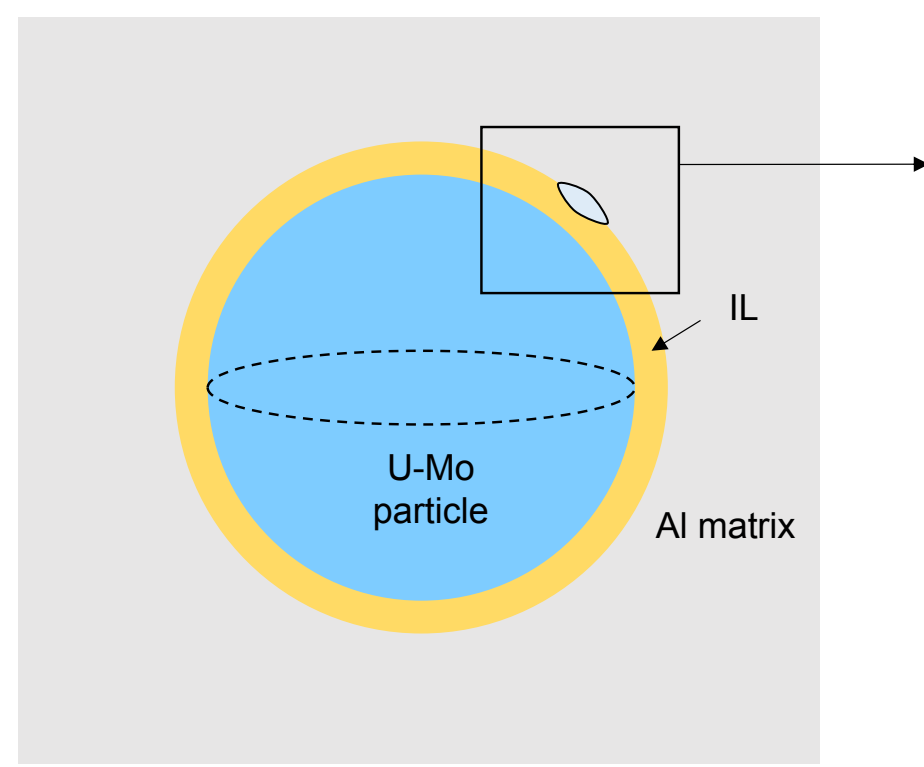

(a)

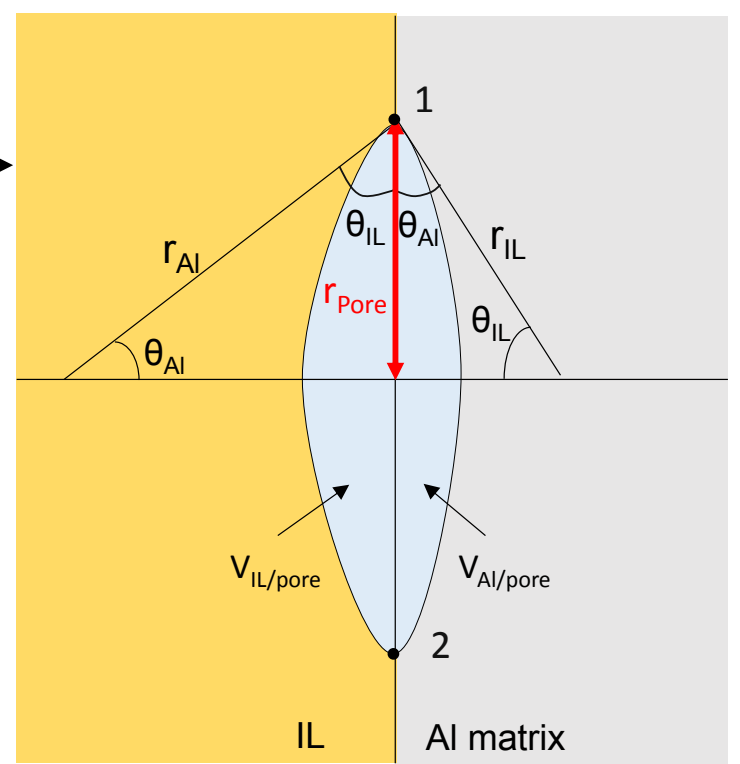

(b)

Fig. 7 Schematics showing (a) the unit cell model composed of a U-Mo particle, IL on the U-Mo, a pore at the IL-Al interface, and the corresponding $\mathrm{Al}$ matrix, (b) the details of the geometrical configuration around the pore. The numbers 1 and 2 stand for vertexes labeled in Table 4. 


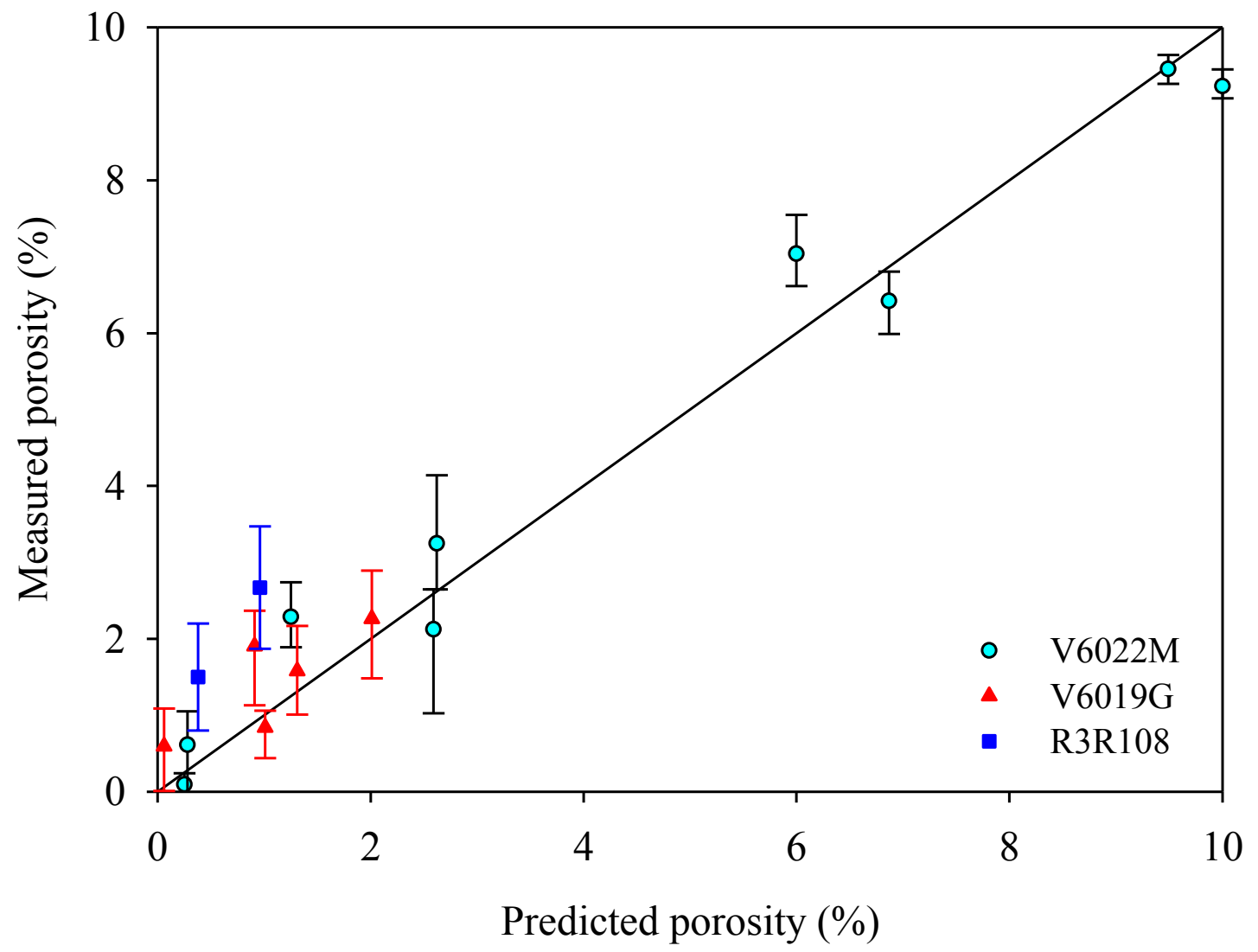

Fig. 8 Comparison between measured and predicted porosities for V6022M, V6019G and R3R108 at the meat end region. 